\title{
BDNF and NT3 Reprogram Human Ectomesenchymal Dental Pulp Stem Cells to Neurogenic and Gliogenic Neural Crest Progenitors Cultured in Serum-Free Medium
}

\author{
Jon Luzuriaga ${ }^{a} \quad$ Jose Ramon Pineda ${ }^{a, b}$ Igor Irastorza ${ }^{a}$ \\ Veronica Uribe-Etxebarria ${ }^{a}$ Patricia García-Gallastegui ${ }^{a}$ \\ Juan Manuel Encinas ${ }^{b, d} \quad$ Pablo Chamero ${ }^{c}$ Fernando Unda ${ }^{a}$ \\ Gaskon Ibarretxe
}

\begin{abstract}
aDepartment of Cell Biology and Histology, Faculty of Medicine and Nursing, University of the Basque Country, UPV/EHU, Leioa, Spain, ${ }^{b}$ Achucarro Basque Center for Neuroscience, UPV/EHU Scientific Park, Leioa, Spain, 'Laboratoire de Physiologie de la Reproduction et des Comportements UMR 0085 INRA/ CNRS/IFCE/Université de Tours, Nouzilly, France, dlkerbasque, The Basque Foundation for Science, Bilbao, Spain
\end{abstract}

\section{Key Words}

Serum-free culture media - Calcium imaging - Cell differentiation • Dental Pulp Stem Cells • Brain Derived Neurotrophic Factor

\begin{abstract}
Background/Aims: Human Dental Pulp Stem Cells (hDPSCs) are one of the most promising types of cells to regenerate nerve tissues. Standard DMEM $+10 \%$ fetal bovine serum (FBS) culture medium allows a fast expansion of hDPSC as a surface-adherent cell monolayer. However, the use of FBS also compromises the clinical use of these protocols, and its longterm presence favors hDPSCs differentiation toward mesenchymal cell-derived lineages, at the expense of a reduced capability to generate neural cells. The objective of this work was to characterize the role of neurotrophin signaling on hDPSCs using a serum-free culture protocol, and to assess the neurogenic and gliogenic capacity of hDPSCs for future nerve tissue bioengineering and regeneration. Methods: We compared the different expression of neurotrophin receptors by RT-PCR, Q-PCR, and IF of hDPSCs cultured with different growth media in the presence or absence of serum. Moreover, we assessed the response of hDPSCs to stimulation of neurotransmitter receptors by live cell calcium imaging under these different media. Finally, we compared the osteogenic potential of hDPSCs by Alizarin red staining, and the differentiation to gliogenic/neurogenic fates by immunostaining for Schwann lineage




\section{Cellular Physiology Cell Physiol Biochem 2019;52:1361-1380 \\ \begin{tabular}{lll} 
and Biochemistry & $\begin{array}{c}\text { DOl: 10.33594/000000096 } \\
\text { Published online: } 11 \text { May 2019 }\end{array}$ & $\begin{array}{l}\text { O } 2019 \text { The Author(s). Published by } \\
\text { Cell Physiol Biochem Press GmbH\&Co. KG }\end{array}$ \\
\cline { 2 - 3 }
\end{tabular} \\ Luzuriaga et al.: BDNF and NT3 Reprogram Human Dental Pulp Stem Cells to Neural \\ Crest Progenitors}

and neuronal lineage markers. We tested a commercial serum-free medium designed for the growth of mesenchymal stem cells: StemPro MSCTM (STP). Results: hDPSCs cultured in STP generated small non-adherent floating dentospheres that showed very low proliferation rates, in contrast to standard FBS-containing medium. We found that hDPSCs grown in STP conditions overexpressed neurotrophin receptor genes NTRK2 (TrkB) and NTRK3 (TrkC). Interestingly, the stimulation of these receptors by adding their respective ligands BDNF and NT-3 to STP medium enhanced the neural crest (NC) progenitor features of cultured hDPSCs. We observed a 10 to 100 -fold increase of migratory NC cell markers $H N K 1$ and $P 75^{N T R}$, and a significant overexpression of pluripotency core factors SOX2, OCT4 and NANOG. Moreover, hDPSCs cultured in BDNF/NT-3 supplemented STP showed a largely increased potential to differentiate towards neuronal and Schwann glial lineage cells, assessed by positive immunostaining for DCX, NeuN and S100B, p75 NTR markers, respectively. Conclusion: Our results demonstrate that the use of BDNF and NT-3 combined with STP induced the partial reprogramming of ectomesenchymal hDPSCs to generate early NC progenitor cells, which are far more competent for neuronal and glial differentiation than hDPSCs grown in the presence of FBS.

(C) 2019 The Author(s). Published by

Cell Physiol Biochem Press GmbH\&Co. KG

\section{Introduction}

Adult human tissues possess their own specific adult stem cell niches, which harbor populations of non-committed multipotent stem cells that are responsible of cell and tissue renewal during adulthood. Those stem cells are usually activated on demand to replenish populations of post-mitotic differentiated cells. Some of the most studied adult stem cell niches include the bone marrow, the subventricular and subgranular zones of the brain, the olfactory epithelium, the skin, the intestine, the adipose tissue, the hair follicles and the dental pulp [1-7]. Dental pulp tissue has been under intense focus by the tissue-engineering field owing to the multifaceted characteristics of the heterogeneous stem cell populations located within it. These are collectively named Dental Pulp Stem Cells (DPSCs) [8-10] and were first described and characterized 18 years ago $[11,12]$. Considering their neural crest (NC) marker expression and remarkable differentiation abilities to osteogenic, adipogenic and chondrogenic lineages they were traditionally regarded as neural crest derived mesenchymal stem cells (MSC), or ectomesenchymal stem cells [13-19]. However, most recent studies showed that the stemness of DPSCs far exceeded their consideration as merely ectomesenchymal cells, because they were able to give rise to non-mesenchymal lineages such as Schwann and endothelial cells as well [20-25]. Most cranial tissues, including teeth, are derived from the NC during embryo development, just like neuronal and glial cells of the peripheral nerve system (PNS). As an evidence of this common origin, it has been shown that hDPSCs can differentiate to neural cell lineages [24, 26-29], exactly like other sources of NC-derived cells distributed throughout the body [30,31]. At present, some populations of human DPSCs (hDPSCs) could be regarded as true early NC progenitors, one step upstream to ectomesenchymal stem cells [32,33]. However, in vitro reprogramming of ectomesenchymal hDPSCs to neurogenic and gliogenic NC progenitors remained largely unexplored.

One important drawback of many of the reported neural differentiation protocols using hDPSCs is the use of fetal serum of animal origin (bovine or calf) added to the culture medium $[28,29]$. Serum favors cell survival but also induces hDPSCs differentiation towards osteo/ odontoblastic lineages. This directly imposes a reduction in the capacity of differentiation towards neuronal or glial cell fates [34-36]. Moreover, the incorporation of xenogenic elements from FBS to hDPSC cultures could be responsible for host immune-reactivity, graft rejection or cell contamination $[37,38]$. Therefore, a vast amount of research is being carried out to establish new serum free culture protocols. Stem cells are defined as cell-based medicinal products (CBMPs) for human therapies. Thus, hDPSCs need to be cultured and prepared under strict and reproducible conditions in order to achieve good manufacturing practice (GMP), a required quality standard described in EU Regulation 2003/94/EC [39]. 


\section{Cellular Physiology Cell Physiol Biochem 2019;52:1361-1380

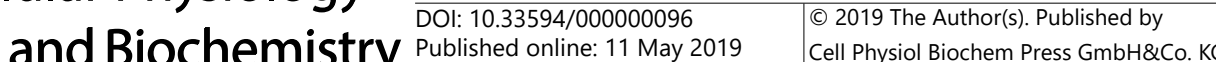 \\ Luzuriaga et al.: BDNF and NT3 Reprogram Human Dental Pulp Stem Cells to Neural \\ Crest Progenitors}

When neural stem/progenitor cells (NSCs) are cultured in vitro with serum free media, it is typical to observe the formation of floating neurospheres $[40,41]$ similarly to other NC-derived cells [34]. Importantly, hDPSCs also have the capacity to form floating spheres (dentospheres) in serum free media, in contrast to the typical surface-attached monolayer morphology that hDPSCs acquire when they are cultured in the presence of FBS $[42,43]$. This unique morphology and culture characteristics of hDPSCs grown as dentospheres has been related to a higher responsiveness to neural differentiation [27, 44]. However, so far there has been no extensive characterization of the physiological changes occurring within hDPSCs dentospheres, especially to what concerned a possible differential activity of specific neural signaling regulators: neurotransmitters and/or neurotrophins. In the present study, we assessed the differentiation potential of hDPSCs to neural cell lineages in both a serumfree specific medium, StemPro MSC ${ }^{\text {mi }}$ (STP) and the standard DMEM+10\% FBS medium.

\section{Materials and Methods}

\section{hDPSC cultures}

Primary hDPSCs were isolated from human third molars from healthy donors between 18 and 40 years of age, who gave their informed consent. Teeth were fractured mechanically, and the dental pulp enzymatically digested by $3 \mathrm{mg} / \mathrm{ml}$ collagenase and $4 \mathrm{mg} / \mathrm{ml}$ dispase (ThermoFisher Scientific, Waltham, Massachusetts, USA) for $1 \mathrm{~h}$ at $37^{\circ} \mathrm{C}$. After centrifugation at $15000 \mathrm{rpm}$ for 5 minutes, cells were mechanically dissociated with 18G needles (BD Microlance). Then, DPSCs were cultured in Dulbecco's modified Eagle's medium (DMEM, Lonza, Basel, Switzerland) supplemented with $10 \%$ of inactivated FBS (Hyclone, GE Healthcare Life Sciences, Logan. UT, USA), 2 mM L-glutamine (Sigma, St. Louis, MO, USA) and penicillin $100 \mathrm{U} / \mathrm{ml}+$ streptomycin antibiotics $150 \mu \mathrm{g} / \mathrm{ml}$ (Gibco, Karlsruhe, Germany). Once the culture was in confluence hDPSCs were subcultured in a fresh defined culture medium named STP, which was composed of StemPro MSC SFM basal medium (Gibco, Karlsruhe, Germany) supplemented with StemPro MSC SFM supplement (Gibco, Karlsruhe, Germany) at 9:1 ratio and in presence of antibiotics penicillin $100 \mathrm{U} / \mathrm{ml}$ and streptomycin $150 \mu \mathrm{g} / \mathrm{ml}$ (Gibco, Karlsruhe, Germany). After 1 week of culture, the STP medium was replaced with STP+NTP medium, consisting in the same formulation described above with the addition of $500 \mathrm{ng} / \mathrm{ml} \mathrm{BDNF}$ (Peprotech, London, UK) and $20 \mathrm{ng} / \mathrm{ml}$ NT-3 (Peprotech, London, UK). Culture media were renewed every 2-3 days. Using this protocol, hDPSCs were maintained in optimal conditions even up to 3 months, with a total accumulation of 6 passages as maximum.

\section{Flow cytometry}

hDPSCs cultured in either DMEM+10\% FBS or STP were enzymatically detached with Trypsin-EDTA (Lonza, Basel, Switzerland) from the surface and then incubated with PBS 0.15\% bovine serum-albumin (BSA) solution with $0.5 \mathrm{mg} / \mathrm{ml}$ of CD90-FITC 1:50 (Biolegend, San Diego, California, USA), CD105-PE 1:50 (eBioscience,Waltham, Massachusetts, USA), CD73-APC 1:50 (eBioscience,Waltham, Massachusetts, USA), CD45-APC 1:50 (Biolegend, San Diego, California, USA) or IgG2a $\kappa$ Isotype control (Biolegend, San Diego, California,USA) for 40 minutes on ice. hDPSCs were washed with PBS $0.15 \%$ BSA after staining, then cells were resuspended in $300 \mu \mathrm{l}$ of PBS $0.15 \%$ BSA and analyzed using a FACS Beckman Coulter Gallios (Beckman Coulter Life Sciences, Indianapolis, United States). Flowing Software 2.5 (University of Turku, Finland) was used for data analysis.

\section{DPSC differentiation protocols}

hDPSCs were initially cultured for 2 weeks using the three abovementioned different culture media (DMEM+10\% FBS, STP, STP+NTP). The initial seeding for all conditions was $15000 \mathrm{cells} / \mathrm{cm}^{2}$ using noncoated cover slips. In order to test differentiation capabilities, culture media for each condition were changed for neurogenic or osteogenic differentiation. Neurogenic induction was achieved using Neurocult ${ }^{\mathrm{TM}}$ medium with differentiation supplement at 9:1 ratio (Stem Cell Technologies, Vancouver, Canada), Heparin at $2 \mu \mathrm{g} / \mathrm{ml}$ (Stem Cell Technologies, Vancouver, Canada), EGF at $20 \mathrm{ng} / \mathrm{ml}, \mathrm{FGFb}$ at $10 \mathrm{ng} / \mathrm{ml}$ (Peprotech, London, UK), 2\% of B27 supplement (Thermofisher, Waltham, Massachusetts, USA) and a mixture of antibiotics penicillin/streptomycin at $100 \mathrm{U} / \mathrm{ml}$ and $150 \mu \mathrm{g} / \mathrm{ml}$ respectively (Gibco, Karlsruhe, Germany). 


\section{Cellular Physiology Cell Physiol Biochem 2019;52:1361-1380 \\ \begin{tabular}{ll|l} 
and Biochemistry $10.33594 / 000000096$ & $\begin{array}{l}\text { Published online: } 11 \text { May } 2019 \\
\text { Pell Physiol Biochem Press GmbH\&Co. KG }\end{array}$ \\
\hline
\end{tabular} \\ Luzuriaga et al.: BDNF and NT3 Reprogram Human Dental Pulp Stem Cells to Neural \\ Crest Progenitors}

For osteogenic differentiation, the culture medium was changed to DMEM+10\% FBS, $20 \mu \mathrm{M} \beta$-glycerolphosphate (Sigma, G9422, St. Louis, MO, USA), 10 nM dexamethasone (D4902, Sigma, St. Louis, MO, USA), and $52 \mathrm{nM}$ ascorbic acid (\#100468, Merck, Darmstadt, Germany) for three weeks.

\section{Alizarin Red assay}

To test osteogenic potential after three weeks of culture, extracellular calcified bone matrix deposits were stained using Alizarin Red. Briefly, hDPSCs were fixed for 30 minutes with $10 \%$ formaline (\#F7503, Sigma, St. Louis, MO, USA), rinsed and stained using 2 g/100 ml Alizarin Red S (\#400480250, Fisher Scientific, Hampton, Nou Hampshire, USA), pH 4.3 for 45 minutes. After three PBS rinses of 5 min, Alizarin Red absorbance was measured at $450 \mathrm{~nm}$ using a Synergy HT Multi-Mode Microplate Reader (Biotek,Winooski, Vermont, USA).

\section{RNA extraction and retrotranscription}

Cell pellets from the different cultures were obtained after trypsin disaggregation and centrifugation and were immediately frozen at $-80{ }^{\circ} \mathrm{C}$ until use. RNA extraction was performed following RNeasy mini kit instructions (Qiagen, Hilden, Germany). RNA concentration was determined using Nanodrop Synergy HT (Biotek, Winooski, Vermont, USA) and purity was calculated by $260 / 280 \mathrm{~nm}$ absorbance ratio. RNA retrotranscription to synthetize cDNA was performed starting from $1000 \mathrm{ng}$ of the total extracted RNA using iScript cDNA Kit (1708890, Biorad, Hercules, California) following manufacturer instructions.

\section{Conventional RT-PCR and Quantitative Real-Time PCR ( $q P C R$ )}

Conventional PCR was performed amplifying cDNA using specific oligonucleotide primers and the commercial My $\mathrm{Taq}^{\mathrm{TM}}$ Red

Mix (\#BIO-25043, Bioline International, Canada) according to the instructions of the manufacturer. The PCR products were finally analyzed by gel electrophoresis in a $2 \%$ agarose gel. Quantitative RealTime PCR were carried out using Power SYBR® Green PCR Master Mix 2x (\#4367659, Applied Biosystems $^{\mathrm{TM}}$, California, USA) and a CFX96 Real-Time System (Biorad, Hercules, California, USA) as previously described [45]. Data were analyzed using Bio-Rad CFX manager software (Biorad, Hercules, California, USA). All reactions were performed in triplicate and the relative expression of each gene was calculated using

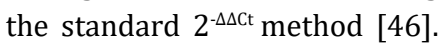
$\beta$-ACTIN and GAPDH were used as housekeeper genes. Primer pairs used for PCR and Q-PCR were obtained from the PrimerBlast method (Primer Bank) and they are listed in Table 1.
Table 1. List of primers used in this study

\begin{tabular}{|c|c|c|c|c|}
\hline Primers & & Sequence $5^{\prime}-3^{\prime}$ & Annealing (Co ) & Amplicon (bp) \\
\hline \multirow{2}{*}{$\beta$-actin } & Upstream & GTTGTCGACGACGAGCG & 58.50 & \multirow{2}{*}{93} \\
\hline & Downstream & GCACAGAGCCTCGCCTT & 59.70 & \\
\hline \multirow{2}{*}{ Nestin } & Upstream & GGTCCTAGGGAATTGCAGC & 57.90 & \multirow{2}{*}{144} \\
\hline & Downstream & CTCAAGATGTCCCTCAGCCT & 58.80 & \\
\hline \multirow{2}{*}{$\beta$ III-Tubulin } & Upstream & CCAGCTGCAAGTCCGAGT & 59.65 & \multirow{2}{*}{141} \\
\hline & Downstream & CGCCCAGTATGAGGGAGAT & 58.25 & \\
\hline \multirow{2}{*}{ Oct 4} & Upstream & CGTGAAGCTGGAGAAGGAGA & 59.11 & \multirow{2}{*}{137} \\
\hline & Downstream & CATCGGCCTGTGTATATCCC & 57.61 & \\
\hline \multirow{2}{*}{ Sox2 } & Upstream & ATAATAACAATCATCGGCGG & 53.64 & \multirow{2}{*}{90} \\
\hline & Downstream & AAAAAGAGAGAGGCAAACTG & 53.72 & \\
\hline \multirow{2}{*}{ Nanog } & Upstream & GTCAAGAAACAGAAGACCAG & 53.88 & \multirow{2}{*}{184} \\
\hline & Downstream & GCCACCTCTTAGATTTCATTC & 54.35 & \\
\hline \multirow{2}{*}{ Snai1 } & Upstream & AACAATGTCTGAAAAGGGAC & 53.69 & \multirow{2}{*}{95} \\
\hline & Downstream & ATAGTTCTGGGAGACACATC & 53.86 & \\
\hline \multirow{2}{*}{ Snai2 } & Upstream & AAACAACCTGAAGACTTGTG & 53.96 & \multirow{2}{*}{157} \\
\hline & Downstream & TTCTTTGTACAGTGGTTTGG & 53.64 & \\
\hline \multirow{2}{*}{ Hnk1 } & Upstream & TGTGAGTGCTGGTAATGAG & 54.51 & \multirow{2}{*}{169} \\
\hline & Downstream & ACTGCCCTCATCCTTATG & 53.17 & \\
\hline \multirow{2}{*}{ Ntrk1 } & Upstream & AAACAAGTTTGGGATCAACC & 54.26 & \multirow{2}{*}{161} \\
\hline & Downstream & CACTGAAGTATTGTGGGTTC & 53.93 & \\
\hline \multirow{2}{*}{ Ntrk2 } & Upstream & TTATGTGGATCAAGACTCTCC & 54.46 & 121 \\
\hline & Downstream & AAACCACAATTGGGTATCTG & 53.43 & 121 \\
\hline Ntrk3 & Upstream & CATACACATAGAGAACTGGC & 53.22 & 100 \\
\hline Nerks & Downstream & AAGTCCTGAGTTCTTGATGG & 54.67 & 100 \\
\hline NGF & Upstream & CCATGTTGTTCTACACTCTG & 53.67 & 125 \\
\hline NGF & Downstream & GGAATGCTGAAGTTTAGTCC & 53.99 & 125 \\
\hline NT_3 & Upstream & CGCAACTACTTTCTTCTCTC & 53.83 & 189 \\
\hline N1-3 & Downstream & CTTGTTCACCTGTAAGATCG & 53.79 & 189 \\
\hline & Upstream & TTACAAAGCTGCTAAAGTGG & 53.82 & \\
\hline Bdnf & Downstream & GAACTGAGATTAGATGGCTTC & 53.82 & 82 \\
\hline P2xr7 & Upstream & TCTTTCCGCTGGTACAGCTT & 59.31 & 149 \\
\hline P2xr7 & Downstream & AGCTGCAGTGATGTTTTCCA & 58.01 & 149 \\
\hline Grik2 & Upstream & ATTGGGCCAGATTCCACATA & 56.55 & 106 \\
\hline GrIKL & Downstream & GCACCGTTAAACTCCTGCTC & 59.20 & 106 \\
\hline Gabhr1 & Upstream & GGGTGTCTTTTCAGTCGCTT & 58.41 & 137 \\
\hline Gabor 1 & Downstream & GATGAGATGACTGAGGCGGT & 59.25 & 137 \\
\hline Gabrb1 & Upstream & TGCAGTTCTGCTCATCCAGT & 59.31 & 145 \\
\hline Gabrb1 & Downstream & AAATCATTTGTGCATGGGGT & 56.15 & 145 \\
\hline Glrb & Upstream & ATAAAGGCACGGGCTACTACA & 58.89 & 141 \\
\hline GIrD & Downstream & CGTCCGGGTTGATCCAGAA & 59.41 & 141 \\
\hline C×26 & Upstream & CATGTACGACGGCTTCTCCAT & 60.20 & 146 \\
\hline Cx26 & Downstream & GCAGGATGCAAATTCCAGACAC & 60.42 & 146 \\
\hline $\mathrm{C} \times 43$ & Upstream & GGTGACTGGAGCGCCTTAG & 60.15 & 225 \\
\hline$c \times 43$ & Downstream & GCGCACATGAGAGATTGGGA & 60.46 & 225 \\
\hline Panx1 & Upstream & GCTCTTTGCGATCCTCCTGTA & 59.86 & \\
\hline PanxI & Downstream & TGCACGGTTGTAAACTTTGTCAA & 59.81 & 118 \\
\hline & Upstream & TAGGCATTGGGGTGAAAGAG & 57.19 & \\
\hline Cav1.2 & Downstream & GAAGATGATTCCAACGCCAC & 57.17 & 125 \\
\hline & Upstream & GCTAAGAGACCCAAACAGGAAC & 58.92 & 210 \\
\hline Nav1.2 & Downstream & GAATCGAGAGATTGCTTTCCCTT & 58.80 & 210 \\
\hline
\end{tabular}




\section{Cellular Physiology Cell Physiol Biochem 2019;52:1361-1380 \\ \begin{tabular}{ll|l} 
and Bioch $10.33594 / 000000096$ & & (c) 2019 The Author(s). Published by \\
Cell Physiol Biochem Press GmbH\&Co. KG
\end{tabular} \\ Luzuriaga et al.: BDNF and NT3 Reprogram Human Dental Pulp Stem Cells to Neural \\ Crest Progenitors}

\section{Immunofluorescence (IF)}

Cells grown on laminin-coated glass coverslips were fixed with $4 \%$ PFA for 10 minutes and washed with PBS. Blocking step was performed by 10 minutes of incubation with Normal Goat Serum (501972, ThermoFisher Scientific, Waltham, Massachusetts, USA) and then coverslips were incubated overnight at $4 \stackrel{\circ}{\circ}$ with the following primary antibodies diluted in PBS $+1 \%$ BSA $+0.1 \%$ Triton X-100: $\beta$ III-Tubulin 1:300 (ab182027, Abcam, Cambridge, UK), Collagen1 1:300 (ab34710, Abcam Cambridge, UK), Ki67 1:100 (ab15580, Abcam, Cambridge, UK), Sox2 1:200, Oct-4 1:200 (ab19857, Abcam Cambridge, UK), Vimentin 1:200 (ab24525, Abcam Cambridge, UK), Glial Fibrillary Acidic Protein (GFAP) 1:400 (MAB3402, Millipore, Lake Placid, NY), Nestin 1:200 (NES, Aves Labs), S100ß 1:1000 (Z0311 Dako, Glostrup, Denmark), NeuN 1:200 (EPR12763, Abcam, Cambridge, UK), Doublecortin (DCX) 1:200 (sc-8066, Santa Cruz, Dallas, TX, USA), Tyrosine Hydroxylase (TH) 1:1000 and GABA 1:100 (ab6211 and ab8891, Abcam, Cambridge, UK), MAP2 1:1000 (M4403, Sigma-Aldrich, St. Louis, USA), TrkB 1:200 (MBS417499, Abyntek Biopharma, Derio, Spain) and TrkC 1:2000 (sc-80403, Santa Cruz technologies, Dallas, USA). After 3 rinses of 5 min using PBS, goat anti-mouse and anti-rabbit secondary antibodies conjugated to Alexa 488 and Alexa 594 were incubated for $2 \mathrm{~h}$ at room temperature. DAPI 1:1000 incubation was used to counterstain cell nuclei. Images were acquired at 20X and 40X magnification with a Zeiss Apotome fluorescent microscope managed by Zen software or Leica Confocal SP8. Fiji software was used to quantify the IF signal in images.

\section{Live cell calcium imaging}

hDPSCs were grown on poly-lysine coated glass coverslips and allowed to grow and make contacts for 7 days. In order to register cell calcium imaging, $5 \mu \mathrm{M}$ fura-2/AM or $2 \mu \mathrm{M}$ fluo-4/AM (Invitrogen, Waltham, Massachusetts, USA) were incubated for 60 minutes at $37^{\circ} \mathrm{C}$. Immediately, coverslips were placed in a flow chamber (Warner Instruments) with constant perfusion of Hank`s balanced salt solution (HBSS, Invitrogen, Waltham, Massachusetts, USA) supplemented with $10 \mathrm{mM}$ Hepes (2-[4-(2-hydroxyethyl) piperazin-1-yl] ethanesulfonic acid) at room temperature. Then, cells were alternately excited at 340 and $380 \mathrm{~nm}$ for fura-2 imaging, recording the emitted light above $510 \mathrm{~nm}$. The F340/380 ratio was used as index of cytoplasmic $\left[\mathrm{Ca}^{2+}\right.$. For fluo-4 imaging, single excitation at $488 \mathrm{~nm}$ and emission at $520 \mathrm{~nm}$ was used and data were plotted as $\Delta \mathrm{F} / \mathrm{F}$, where $\Delta \mathrm{F}=\mathrm{F}-\mathrm{F}_{0} \mathrm{~F}$ is the fluorescence intensity of agonist-containing solution and $\mathrm{F}_{0}$ is the fluorescence intensity of control solution. Recordings were performed using a C10600-10B Hamamatsu camera installed on an Olympus IX71 microscope. Data analysis was performed using manually selected regions of interest (ROI), including background subtraction using Fiji software. Results are based on recordings from hDPSCs of 3-4 patients cultured in with DMEM/FBS, STP, and STP+BDNF and NT-3 (NPS) culture media.

\section{ELISA}

BNDF and NT3 content were determined in duplicate by the R\&D DuoSet Immunoassay (R\&D) as described previously (Canals et al., 2004). Briefly, 250.000 cells were seeded in T75 flasks with $5 \mathrm{~mL}$ of either DMEM or STP and culture media were collected after 7days of seeding. We analyzed $100 \mu \mathrm{L}$ of supernatants and lysed cell pellet from cell culture diluted 1:1 in reagent buffer $1 X$. Values were normalized and expressed as picogram of neurotrophins per $\mathrm{mL}$ and cell. At day 7 the total number of cells were counted using an automated TC20 cell counter (Bio-Rad) to determine the amount of BDNF and NT-3 secreted per cell at the end of the experiment. Quantifications were performed generating a four parameter logistic (4PL) curve fit following the manufacturer instructions.

\section{Statistical analyses}

All results are presented as mean \pm standard error, also referred as SEM. Statistical comparisons were performed through either a Mann Whitney U test or Student's t-test for single comparisons, and either Kruskal-Wallis or a one-way ANOVA, followed by post-hoc tests, for multiple comparisons. Statistical tests were performed by IBM SPSS Statistics v.22. Statistical significance was considered to be *p $\leq 0.05$, ** $\mathrm{p} \leq$ $0.01,{ }^{* * *} \mathrm{p} \leq 0.001$. 


\section{Cellular Physiology Cell Physiol Biochem 2019;52:1361-1380 \begin{tabular}{ll|l} 
and Biochemistry $\begin{array}{l}\text { DOl: 10.33594/000000096 } \\
\text { Published online: 11 May 2019 }\end{array}$ & $\begin{array}{l}\text { O } 2019 \text { The Author(s). Published by } \\
\text { Cell Physiol Biochem Press GmbH\&Co. KG }\end{array}$ \\
\cline { 2 - 3 } &
\end{tabular} \\ Luzuriaga et al.: BDNF and NT3 Reprogram Human Dental Pulp Stem Cells to Neural \\ Crest Progenitors}

\section{Results}

\section{hDPSC proliferation and phenotype marker characterization in both serum-containing}

DMEM and serum-free STP media

To assess the capacity of hDPSCs to undergo neural and glial differentiation without the use of serum, we selected STP as a serum-free medium commercialized for the in vitro culture of mesenchymal stem cells. We found that hDPSC in STP generated small dentospheres (Fig. 1a) as previously reported in other studies using different serum-free media [27, 42, 43]. Dentosphere culture has been reported to reproduce the characteristics and physiology of typical neural stem cell (NSC) neurospheres [40]. We determined that dentospheres were positive for Nestin, a typical NSC marker (Fig. 1a). Dentospheres cultured with STP could be maintained in a very slow proliferative state for several months.

Fig. 1. Characterization of hDPSCs cultures in DMEM+10\% FBS and STP media: a) Different growth patterns depending on the culture medium. Migrating adherent cells soon colonize the whole plating surface in DMEM $+10 \%$ FBS. In contrast, floating dentospheres persist in STP medium, with occasional emergence of long spindle-like adherent cells. IF; images showing expression of mesenchymal markers (Collagen I) and neural markers (Nestin, $\beta 3-T u b u l i n)$ in hDPSCs in both DMEM+10\% FBS and STP culture media. Scale Bar $50 \mu \mathrm{m}$. b) Conventional RT-PCR derived electrophoresis gel bands showing the expression of mesenchymal genes, neural genes and pluripotency core factor genes in both conditions. c) Cell cycle analysis by propidium iodide flow cytometry of hDPSCs grown in both culture media, showing a limitation of the growth rate in STP medium, with respect to DMEM+10\% FBS. d) Flow cytometry analysis for mesenchymal and hematopoietic stem cell markers (CD90, CD105, CD73, CD45) confirmed a generalized ectomesenchymal phenotype of hDPSCs in both media conditions.

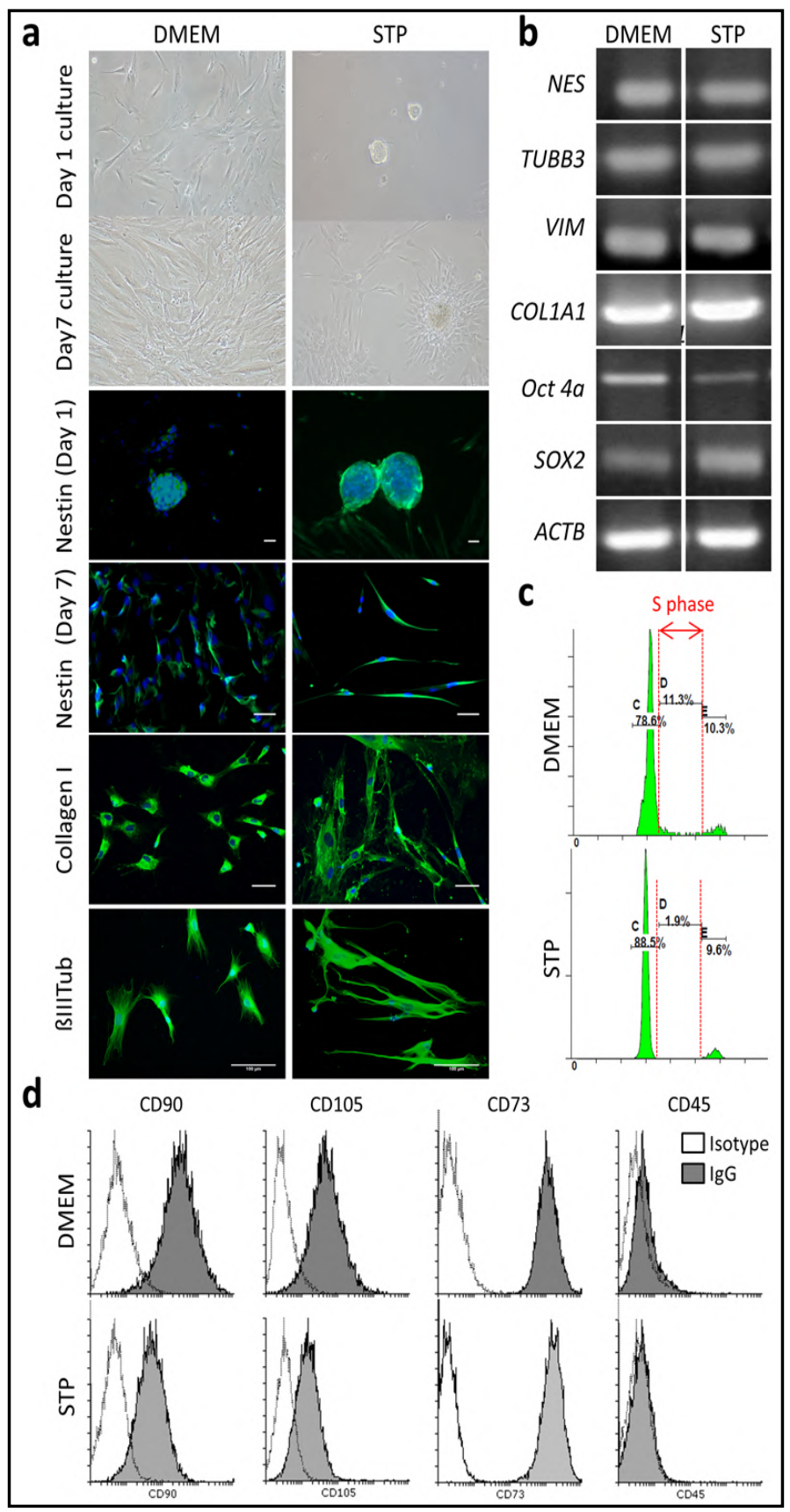




\section{Cellular Physiology Cell Physiol Biochem 2019;52:1361-1380 \\ \begin{tabular}{ll|l} 
and Biochemistry & $\begin{array}{l}\text { DOl: 10.33594/000000096 } \\
\text { Published online: } 11 \text { May } 2019\end{array}$ & $\begin{array}{l}\text { O } 2019 \text { The Author(s). Published by } \\
\text { Cell Physiol Biochem Press GmbH\&Co. KG }\end{array}$ \\
\cline { 2 - 3 } &
\end{tabular} \\ Luzuriaga et al.: BDNF and NT3 Reprogram Human Dental Pulp Stem Cells to Neural \\ Crest Progenitors}

In sharp contrast, hDPSCs grown using DMEM $+10 \%$ FBS formed small adherent colonies that boosted in a rapid cellular proliferation and created a confluent monolayer culture after one-two weeks (Fig. 1a). Despite these different cell morphology and dynamics, flow cytometry analysis showed no differences of expression of the main mesenchymal markers; CD90 (DMEM: 97.3 $\pm 2.09 \%$; STP: 93.4 $\pm 2.23 \%$ ), CD105 (DMEM: 93.1 $\pm 4.5 \%$; STP: 88.1 $\pm 1.79 \%$ ) and CD73 (DMEM: 99.8 $\pm 0.08 \%$; STP: $99.95 \pm 0.02 \%$ ). Cells were negative for hematopoietic stem marker CD45, excluding blood contamination (Fig. 1d). In agreement with that, immunofluorescence staining showed $100 \%$ of cells being positive for mesenchymal/ connective marker Collagen I and neural Nestin and BIII-Tubulin markers (Fig. 1a). These results were also confirmed by RT-PCR (Fig. 1b) where those markers showed a similar expression in different culture media. These three markers were also maintained in hDPSCs during all culture passages (data not shown).

Next we sought to determine if those different culture media could affect cell proliferation. For this purpose, we incubated hDPSCs with propidium iodide to visualize their cell cycle profile. We determined that $78.6 \%$ of total cells were in G0/G1 phase and $21.6 \%$ in S/G2 phase for DMEM+10\% FBS hDPSCs cultures. In contrast, hDPSCs cultured with STP showed a marked decrease of cells in S/G2 phase to a $10.5 \%$, together with an increase to $88.5 \%$ in G0/G1 phase (Fig 1c). To confirm these results, IF against the proliferation marker Ki67 was performed. $25.2 \pm 4.15 \%$ of cells were Ki67-positive for DMEM $+10 \%$ FBS, which were reduced to $10.2 \pm 2.64 \%$ in STP conditions $\left(^{*}=\mathrm{p}<0.022\right.$ Student's t-test. Fig. $\left.1 \mathrm{c}\right)$. In conclusion, both types of culture media maintained the main mesenchymal characteristics of hDPSC, but the STP culture in the absence of serum reduced the S phase of hDPSCs, delaying their proliferative growth.

hDPSCs expressed functional neurotransmitter receptors, voltage-dependent ion channels, and GAP junctions

Because hDPSCs are regarded as a very promising source of stem cells for nerve tissue regeneration [15], we sought to determine whether our cells expressed the principal neurotransmitter receptor families. Thus, we screened for the principal ionotropic and metabotropic receptors for GABA, glutamate, acetylcholine, glycine and ATP, by conventional RT-PCR. Since many of those receptors are multi-heteromeric proteins, only the most important and widely characterized subunits were analyzed for each of them. We found that DPSCs strongly expressed GABA-A (GABBR1), GABA-B (GABRB1), ionotropic ATP receptor (P2XR7), glutamate (kainate subtype (GRIK2)) and glycine (GLRB) receptor subunits (Fig. 2b). In contrast, acetylcholine (CHRNA6), Glutamate ionotropic AMPA (GRIA1) and NMDAreceptor (GRIN1) subunits were only detected in marginal amount (data not shown). We also found that hDPSCs presented a high expression of L-type Voltage-dependent $\mathrm{Ca}^{2+}$ channel (VDCC) subunits (CAV 1.2; Fig. 2d). Taking all these results in consideration and keeping in mind that some of the detected subunits belonged to excitatory ionotropic receptors (kainate and ATP receptors), it was plausible that hDPSCs could undergo a cell-membrane depolarization after their activation. In order to test this, we assessed the functionality of these receptors in hDPSCs by Fluo- 4 and Fura- $2 \mathrm{Ca}^{2+}$ imaging. Whether directly induced by $\mathrm{Ca}^{2+}$ permeation, or indirectly triggered by secondary activation of VDCCs (if the receptors were functional), we speculated that the selective activation of these receptors by their pharmacological agonists would cause an increase in intracellular $\mathrm{Ca}^{2+}$ concentration in hDPSCs. To test this, we transiently stimulated the respective receptors with a pulse of $30 \mathrm{~s}$ of $50 \mu \mathrm{M}$ kainate and $100 \mu \mathrm{M}$ ATPyS respectively. We recorded hDPSCs showing intense $\mathrm{Ca}^{2+}$ increases (Fig. 2a-c; Supplementary Movies 1 and 2) which returned to steady basal $\mathrm{Ca}^{2+}$ levels after agonist stimulation (for all supplemental material see www.cellphysiolbiochem. com). Some hDPSCs responded to more than one agonist (ATP $\gamma$ S, kainate) whereas others were completely insensitive to any stimulation. This result indicated a large degree of cell heterogeneity within each hDPSC culture. When assessing the effect of different culture media (DMEM+10\% FBS vs STP) on the response rate of hDPSCs to ATP $\gamma$ S and Kainate, we only found statistically significant differences for ATP $\gamma \mathrm{S}$ (Fig. 2g). Additionally, we also found 


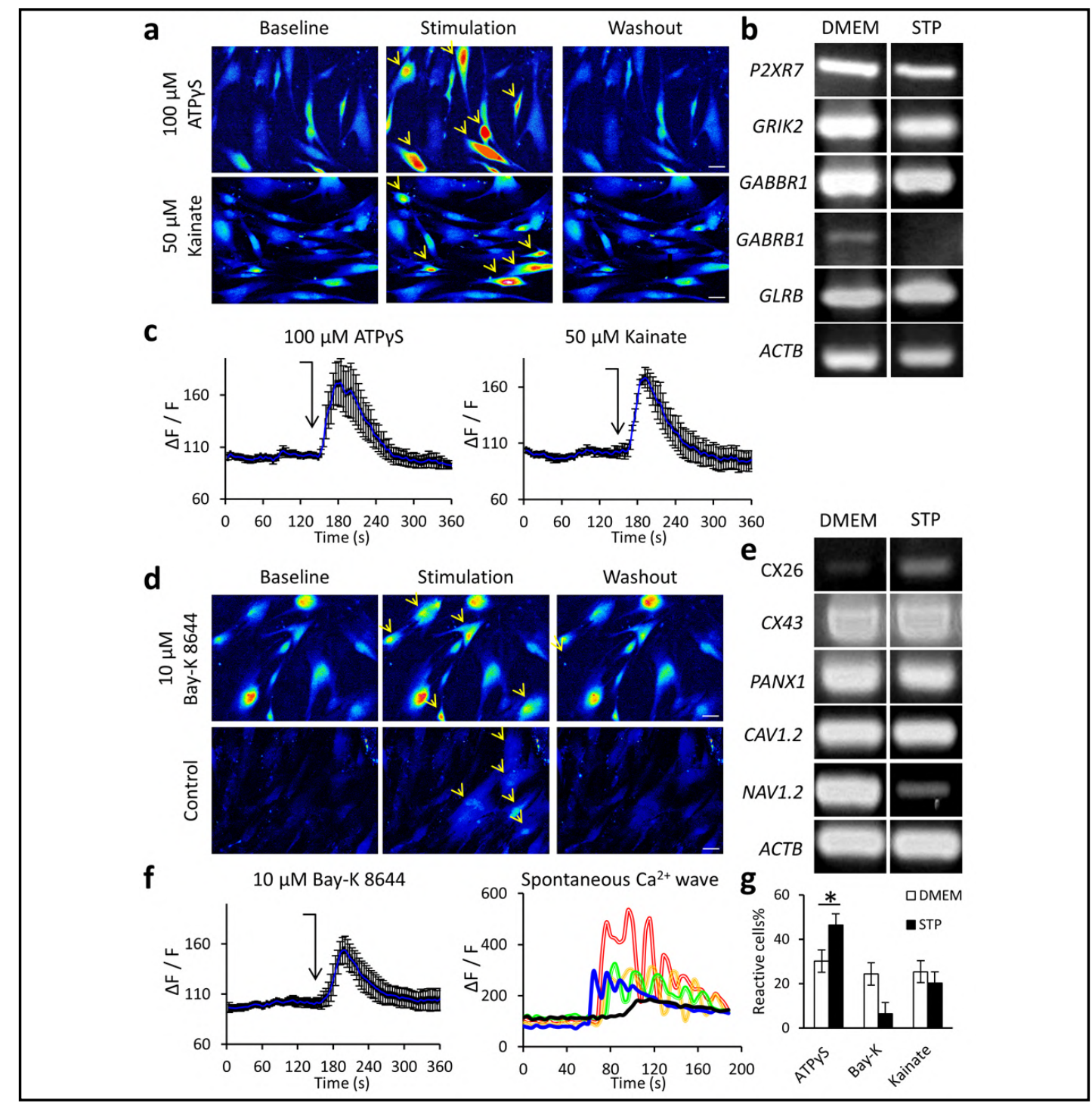

Fig. 2. Presence of functional neurotransmitter receptors, voltage-dependent $\mathrm{Ca}^{2+}$ channels, hemichannels and GAP junctions on hDPSCs: a) Some hDPSC showed functional $\mathrm{Ca}^{2+}$ responses (yellow arrows) to stimulation with $50 \mu \mathrm{M}$ Kainate and $100 \mu \mathrm{M}$ ATPYS. Scale bar $50 \mu \mathrm{m}$. b) Conventional RT-PCR bands showing expression of subunits of neurotransmitter receptors P2XR7 (ATP), GRIK2 (Kainate), GABBR1 (GABAB), GABRB1 (GABAA), GLRB (Glycine). c) Plotting of Fluo-4 fluorescence live measurements before and after stimulation of hDPSCs for $30 \mathrm{~s}$ with $50 \mu \mathrm{M}$ Kainate and $100 \mu \mathrm{M}$ ATPyS. Mean \pm SEM. $\Delta \mathrm{F} / \mathrm{F}$ Fluo4 fluorescence signal of different hDPSCs within a same coverslip ( $n=14$ and 6, respectively). d) hDPSCs showed functional $\mathrm{Ca}^{2+}$ responses to stimulation with $10 \mu \mathrm{M}$ Bay-K 8644 (yellow arrows). Regions of cell confluence occasionally showed spontaneously propagating calcium waves. Scale bar $50 \mu \mathrm{m}$. e) Conventional RT-PCR bands showing expression of Connexin (CX26, CX43) and Pannexin (PANX1) subunits, and L-type voltage gated calcium (Cav1.2) channel subunits and sodium channels (Nav1.2). f) Plotting of Fluo-4 fluorescence live measurements before and after stimulation of hDPSCs for $30 \mathrm{~s}$ with $10 \mu \mathrm{M}$ Bay-K 8644, and spontaneous $\mathrm{Ca}^{2+}$ wave recorded on confluent hDPSCs in the absence of pharmacological stimulation. g) Global quantifications of $\mathrm{Ca}^{2+}$ responsive hDPSCs to different pharmacological treatments. Percentage of hDPSC responding cells vs total cells in cultures grown with DMEM+10\% FBS or STP media. Global rates of response to ATPYS, Bay-K 8644 and Kainate were analyzed ( $\mathrm{n}=50$ to 100 cells from 3 independent hDPSCs cultures). Statistics were analyzed by Mann Whitney ${ }^{*}=\mathrm{p}<0.05$. Movies $1-4$ corresponding to frames shown in a) and d) are available as supplementary material. Supplementary Movie 5 also shows the triggering of $\mathrm{Ca}^{2+}$ waves by stimulation with ATPYS, Bay-K 8644 and Kainate in confluent cells. 


\section{Cellular Physiology and Biochemistry

$\mathrm{Ca}^{2+}$ responses in hDPSCs tested with the specific L-type VDCCs agonist $10 \mu \mathrm{M}$ Bay-K 8644 (Fig. 2d, 2f; Supplementary Movie 3). The rate of response to Bay-K 8644 decreased in STP medium cultured cells (Fig. 2g). Interestingly, $67 \%$ of the cells that responded to ATP $\gamma \mathrm{S}$ and/ or kainate did not respond to Bay-K 8644 (not shown), indicating that the observed $\mathrm{Ca}^{2+}$ transients in these cells likely originated from receptor activity, with little or no contribution by L-type VDCCs.

We also observed that confluent hDPSCs occasionally presented spontaneous and synchronous $\mathrm{Ca}^{2+}$ oscillations, which propagated as waves along all the cell monolayer (Fig. $2 \mathrm{~d}$, 2 fand Supplementary Movie 4). Importantly, $\mathrm{Ca}^{2+}$ waves could also be triggered by application of kainate, ATP $\gamma \mathrm{S}$ and Bay-K 8644 to confluent hDPSC cultures in either DMEM+10\% FBS, STP or STP+NTP conditions (Supplementary Movie $5 \& 6$ ). This synchronous $\mathrm{Ca}^{2+}$ activity on cell cultures was characteristic of cell coupling through GAP junctions. Thus, we analyzed by RT-PCR the expression of Connexin (CX43) and Pannexin (PANX1) subunits, showing a high

Fig. 3. Expression of Neurotrophin ligands and receptors in hDPSCs grown in DMEM+10\% FBS and STP media: a) hDPSC grown in DMEM+10\% FBS and STP express n e u rotrophin receptors, as assessed by conventional RTPCR. b) Changes in the expression levels of neurotrophin receptor coding genes NTRK1, NTRK2 and NTRK3 as assessed by Q-PCR. Significantly higher levels of expression were found in NTRK2 and NTRK3 for STPgrown hDPSCs. Mann Whitney ${ }^{* *}=\mathrm{p}<0.01$. c) Expression levels of TrkB and TrkC in hDPSCs for 7 days in DMEM or STP culture media.

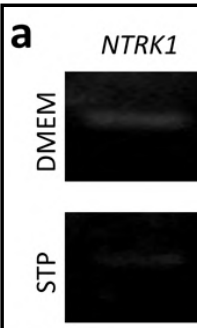

C
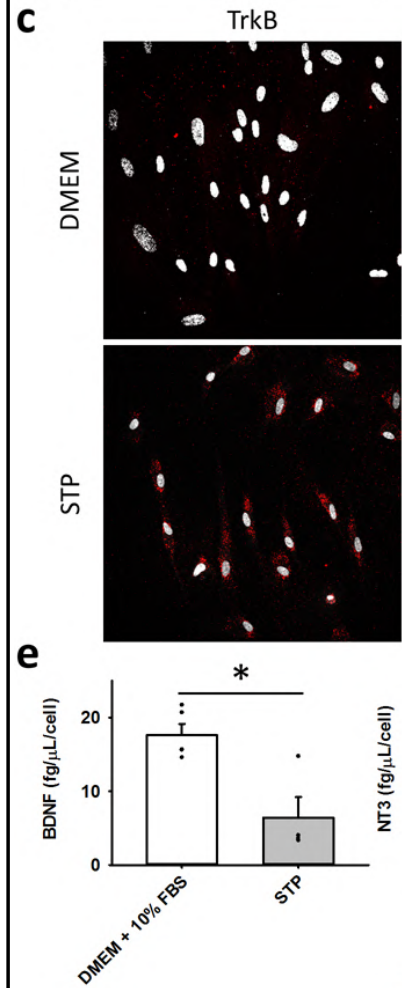
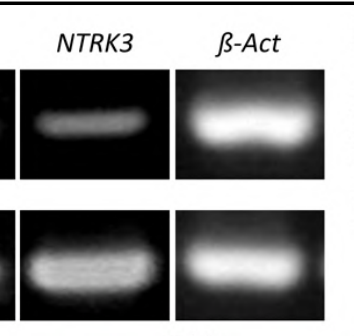

TrkC
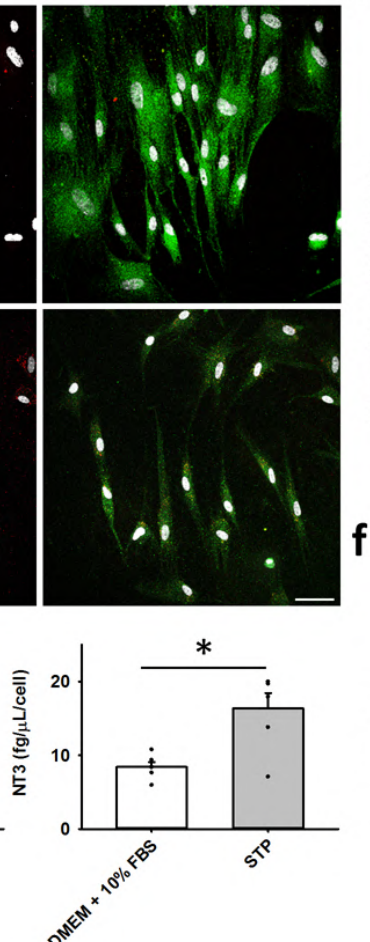
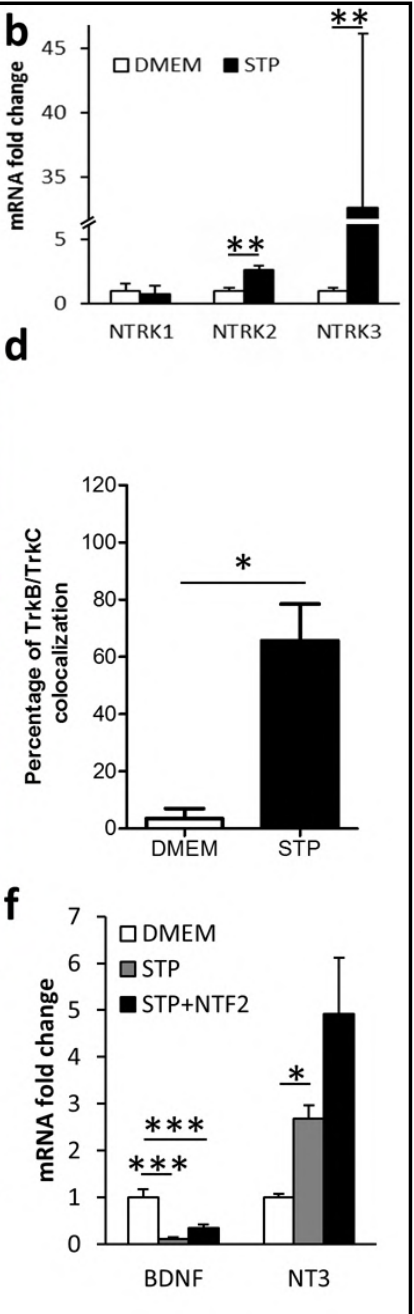

Quantification of

percentage of cells colocalizing both TrkB ansd TrkC receptors. Scale bar $50 \mu \mathrm{m}$. e) hDPSCs cultured using STP media significantly reduced the release of BDNF (left) and increased the release of NT-3 (right). Data were analyzed by Mann-Withney ${ }^{*}=\mathrm{p}<0.05$. Experiments were performed in triplicate. f) Changes in the expression levels of neurotrophin ligands in DMEM+10\% FBS, STP and STP/NTF2 conditions by Q-PCR. Significantly higher levels of expression were found for NT-3 on both STP and STP/NTF2 media. Statistics were analyzed by ANOVA following by Scheffe post-hoc analysis. ${ }^{*}=p<0.05, * * *=p<0.001$. Experiments were performed in triplicate. 


\section{Cellular Physiology Cell Physiol Biochem 2019;52:1361-1380 \\ \begin{tabular}{ll|l} 
and Biochemistry & $\begin{array}{l}\text { DOl: 10.33594/000000096 } \\
\text { Published online: 11 May 2019 }\end{array}$ & $\begin{array}{l}\text { O } 2019 \text { The Author(s). Published by } \\
\text { Cell Physiol Biochem Press GmbH\&Co. KG }\end{array}$ \\
\cline { 2 - 3 } &
\end{tabular} \\ Luzuriaga et al.: BDNF and NT3 Reprogram Human Dental Pulp Stem Cells to Neural \\ Crest Progenitors}

expression of both in hDPSCs grown in either DMEM+10\% FBS or STP (Fig. 2e). This result highlighted that hDPSCs could functionally coordinate and communicate by responding through $\mathrm{Ca}^{2+}$ waves to activation of the principal excitatory receptors.

hDPSCs overexpressed neurotrophins and neurotrophin receptors in serum-free STP medium

The consolidation and maintenance of nerve circuitry imply the establishment of neuronal connectivity during development, requiring the proper signaling of both neurotransmitters and neurotrophins as proposed by the thropic theory [47]. Neurotrophins are classified as an important family of neural growth factors comprised of four ligands: NGF, BDNF, NT-3, NT-4/5, and its receptors: of high affinity NRTK1/TrkA, NTRK2/TrkB, and NTRK3/TrkC, and the low-affinity co-receptor p75 ${ }^{\text {NTR }}$ [48]. Neurotrophic signaling is of utmost importance for both neuronal growth and survival. For this reason, we examined whether DMEM $+10 \%$ FBS or STP culture media could provoke changes in neurotrophin ligand and/or receptor expression on hDPSCs. Conventional RT-PCR showed expression of the three neurotrophin ligands NGF, BDNF and NT-3 (Fig. 3a), as well as for their respective high affinity tyrosine kinase receptors TrkA/NTRK1, TrkB/NTRK2 and TrkC/NTRK3 (Fig. 3b). RT-PCR band for NTRK1 was lighter than for NTRK2 and NTRK3 in both DMEM+10\% FBS and STP culture conditions (Fig. 3a) so we decided to quantify their relative levels of expression by Q-PCR. Interestingly, we found out that NTRK2 and NTRK3 were quite over-expressed in STP, especially NTRK3, whose levels increased $\sim 30$ fold with respect to DMEM+10\% FBS (Fig. $3 b)$. We confirmed this result by IF for the respective receptors TrkB and TrkC (Fig. 3c). We quantified the number of cells that were positive for both receptors and we found an increase of $65.6 \pm 12.85 \%$ of double colocalization in STP cultures $\left(^{*}=p<0.0179\right.$, Student's t-test, Fig. 3d). These changes prompted us to hypothesize that DPSCs in STP medium could be more sensitive to their natural ligands, BDNF and NT-3, with respect to standard medium, and probably, this could have also implications in hDPSCs differentiation.

First of all, we decided to measure secreted neurotrophin levels in both DMEM and STP media. For this purpose, hDPSCs cultures were kept for 7 days in each respective culture

Fig. 4. Expression of neural crest and pluripotency core factors in hDPSCs grown in DMEM+10\% FBS, STP and STP/NTF2 media: a-b) Q-PCR assessment of expression levels of neural crest genes SLUG, SNAIL, HNK1 and $P 75^{\text {NTR }}$ in hDPSCs grown in DMEM+10\% FBS, STP and STP/NTF2. Significantly higher levels of expression were found for migratory NC markers $H N K 1$ and $P 75^{N T R}$ in hDPSCs grown in BDNF/NT-3-supplemented STP (STP + NTF2) ${ }^{*} \mathrm{p}<0.05$ and ${ }^{* *} \mathrm{p}<0.01$. c) Pluripotency factor genes SOX2, OCT4, and NANOG expression levels in DMEM+10\% FBS, STP and STP + NTF2. Higher expression levels were found for the three core factors in BDNF/NT-3supplemented STP (STP + NTF2) conditions. $* * *=p<0.001$. d) Ki67 proliferation marker positive cell percentage of hDPSCs grown in all three culture media, showing a limitation of the growth rate in STP medium, with respect to DMEM+10\% FBS and STP+NTF2. Statistics were analyzed by ANOVA following by Scheffe or Bonferroni post-hoc analysis. Experiments were performed in triplicate.

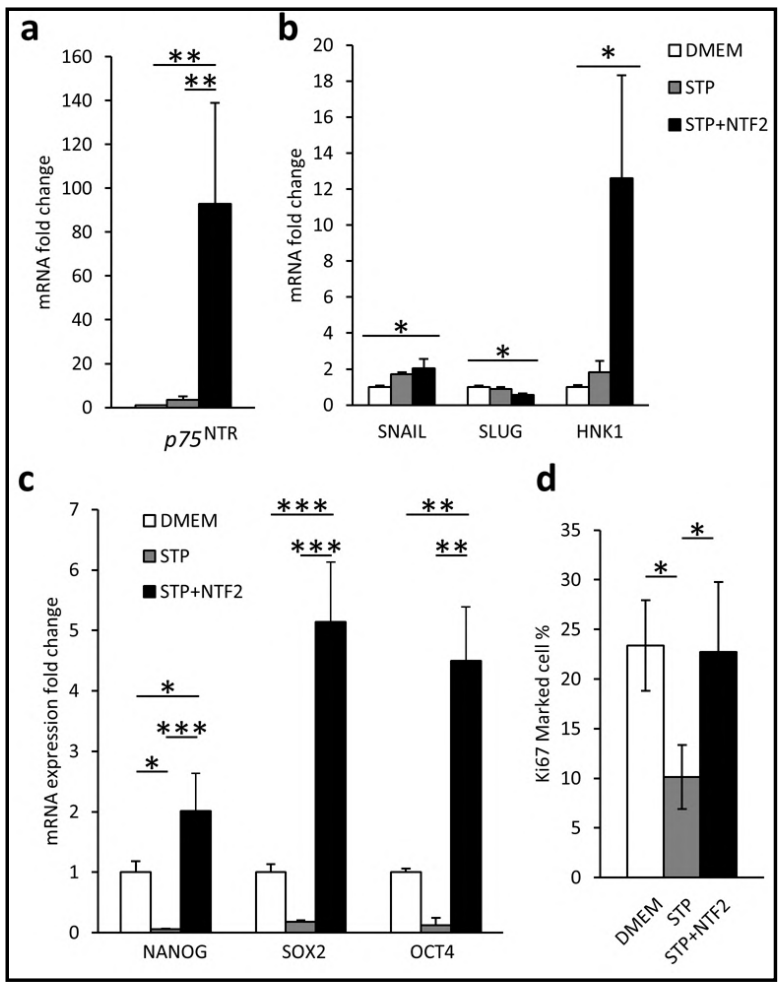




\section{Cellular Physiology Cell Physiol Biochem 2019;52:1361-1380 \begin{tabular}{ll|l} 
and Biochemisty $10.33594 / 000000096$ & C) 2019 The Author(s). Published by \\
Published online: 11 May 2019 & Cell Physiol Biochem Press GmbH\&Co. KG
\end{tabular}

medium and ELISA quantitative assay on supernatants detected $17.66 \pm 1.47 \mathrm{fg} / \mu \mathrm{L} /$ cell and $8.41 \pm 0.66 \mathrm{fg} / \mu \mathrm{L} /$ cell of BDNF and NT-3 with DMEM $+10 \% \mathrm{FBS}$ and $6.44 \pm 2.77 \mathrm{fg} / \mu \mathrm{L} / \mathrm{cell}$ and $16.36 \pm 2.08 \mathrm{fg} / \mu \mathrm{L} /$ cell of BDNF and NT-3 with STP (Fig. 3e). This result demonstrated that STP conditions reduced and increased significantly the release of BDNF and NT-3 respectively ${ }^{*}=\mathrm{p}<0.032$ and $\mathrm{p}<0.041$ Mann-Whitney, Fig 3e). To assess the effect of neurotrophin receptor activation on hDPSCs, we chose to supplement STP medium with $500 \mathrm{ng} / \mathrm{ml}$ of BDNF and 20 $\mathrm{ng} / \mathrm{ml}$ of NT-3 for 7 days, based on previous reports $[49,50]$. First, we assessed whether this supplementation (STP+NTF2) would influence de novo neurotrophin gene expression by hDPSCs. We found a silencing of $B D N F$ expression in STP and STP+NTF2 conditions, and an overexpression of NT-3 in STP, with respect to standard DMEM+10\% FBS (Fig. 3f).

The low affinity neurotrophin co-receptor P75 ${ }^{\mathrm{NTR}}$ is crucial for Trk signaling $[51,52]$ and it is also an important marker of differentiation for certain cell types of the peripheral nerve system [53]. In BDNF/NT-3-treated hDPSC cultures, $p 75 N T R$ expression increased up to $\sim 90$ fold (Fig 4a). Thus, we wondered whether STP supplementation with BDNF and NT-3 promoted differentiation of hDPSCs towards neural lineages, as expected for neurotrophic signaling on adults $[54,55]$. In order to check this, we evaluated the expression of a battery of markers for immature and mature neurons (DCX, NeuN), Schwann cells (S100 $\beta$ ), adult myelinating cells (PLP1), and astrocytes (GFAP) by conventional RT-PCR and IF. All of these markers were either completely absent or only marginally expressed (GFAP) in hDPSCs cultured in any medium (DMEM+10\% FBS, STP, or STP+NTF2; data not shown). In conclusion, STP supplementation with BDNF and NT-3 did not induce hDPSC differentiation to neural cells.

Fig. 5. Immunofluorescence analysis of OCT4 and $\mathrm{P}^{\mathrm{NTR}}$ in hDPSCs grown in DMEM+10\% FBS, STP and STP/NTF2 media: a) OCT4 immunostaining for DMEM+10\% FBS, STP and STP/NTF2 growing hDPSCs. A higher IF nuclear signal corresponding to the active form of OCT4 is found in hDPSCs grown in BDNF/ NT-3-supplemented STP. Scale Bar $50 \mu \mathrm{m}$. b) Graph showing quantification of nuclear OCT4 IF intensity per cell $\left(n=3 .{ }^{*}=p<0.05\right.$. c) $\mathrm{P}^{\mathrm{NTR}}$ immunostaining for DMEM+10\% FBS, STP and STP/NTF2 growing hDPSCs. A higher IF signal for P75 ${ }^{\mathrm{NTR}}$ is found in hDPSCs grown in raw STP and BDNF/NT3supplemented STP $(n=3)$. Scale Bar $50 \mu \mathrm{m}$. d) Graph showing quantification of P75 ${ }^{\text {NTR }}$ IF signal in each condition. All statistics were analyzed by ANOVA following by Scheffe post-hoc analysis

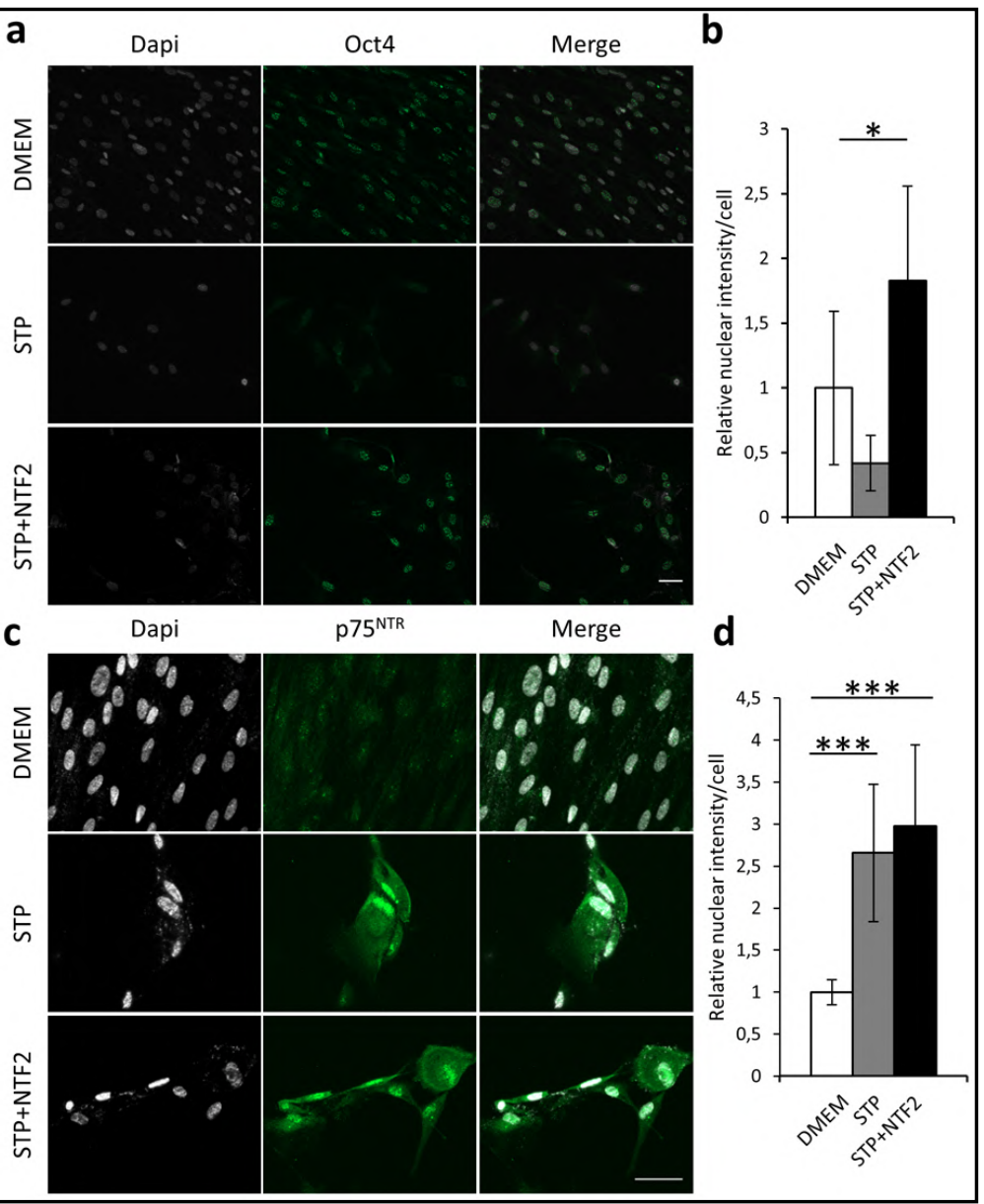
${ }^{*}=\mathrm{p}<0.05{ }^{* * *}=\mathrm{p}<0.001$. Experiments were performed in triplicate. 


\section{Cellular Physiology Cell Physiol Biochem 2019;52:1361-1380 \\ \begin{tabular}{ll|l} 
and Biochemistry & $\begin{array}{l}\text { DOl: 10.33594/000000096 } \\
\text { Published online: } 11 \text { May } 2019\end{array}$ & $\begin{array}{l}\odot 2019 \text { The Author(s). Published by } \\
\text { Cell Physiol Biochem Press GmbH\&Co. KG }\end{array}$ \\
\cline { 2 - 3 }
\end{tabular} \\ Luzuriaga et al.: BDNF and NT3 Reprogram Human Dental Pulp Stem Cells to Neural \\ Crest Progenitors}

Supplementation of STP with BDNF and NT-3 induced hDPSCs to acquire characteristics of early non-committed Neural Crest Stem Cells

During embryonic development, hDPSCs originate from NC stem cells that migrate dorsoventrally from the neural tube to the pharyngeal arches to form most craniofacial tissues, including the dental pulp. Those migratory cells specifically express certain markers such as P75 ${ }^{\mathrm{NTR}}$ and HNK1 [56]. Additionally, NC stem and progenitor cells also express core factors associated to cell pluripotency, such as OCT4a, SOX2 and NANOG [16, 34]. Given that BDNF/NT-3 supplemented-STP did not induce any differentiation of hDPSCs toward mature neural lineages, we wondered if the exposure to neurotrophins would have somehow an impact on hDPSCs stemness. Thus, we first analyzed the expression of NC and pluripotency core factors by hDPSCs on different media conditions. Remarkably, as assessed by Q-PCR, expression of the migratory NC markers HNK-1 increased $\sim 10$ fold, in hDPSCs grown in BDNF/ NT-3-supplemented STP medium, with respect to DMEM+10\% FBS (Fig. 4b). Expression of the core factors OCT $4 a$, SOX2 and NANOG was markedly and consistently increased $\sim 2-5$ fold in BDNF/NT-3-STP medium (Fig. 4c). Interestingly, expression of core factors dropped markedly in raw STP medium with respect to DMEM+10\% FBS, to recover sharply in neurotrophin-supplemented STP medium. This recovery of stemness marker expression mediated by BDNF/NT-3 followed a recovery in the number of proliferating cells assessed by IF against Ki67 (Fig. 4d). IF against P75 ${ }^{\mathrm{NTR}}$ and OCT4 confirmed these changes in cell phenotype (Fig. 5a-d). Therefore, our results indicated that STP supplementation with BDNF and NT-3 reversed quiescence of hDPSCs and the so-derived cells acquired characteristics of non-committed P75 ${ }^{\mathrm{NTR}}+/ \mathrm{HNK} 1+$ neural crest stem cells.

Preconditioning by BDNF/NT-3-STP medium rendered hDPSCs more responsive to neural differentiation protocols

Despite showing a larger expression of pluripotency core factors and NC markers, hDPSCs grown in BDNF/NT-3-STP medium completely lost the ability to respond to osteogenic differentiation media, as assessed by alizarin Red staining (Supplementary Fig. 1). Thus, we hypothesized that the neurotrophin treatment could actually be reprogramming hDPSCs to a prior stage of NC lineage commitment. Then BDNF/NT-3-exposed hDPSCs would have an increased capacity to differentiate to neural cells, at the expense of a reduced capacity to differentiate to mesenchymal lineage cells. To test that hypothesis we used Neurocult ${ }^{\mathrm{TM}}$ differentiation medium, which is widely used to drive neuronal and glial differentiation of neural stem cells [57]. hDPSCs were grown in three different media conditions (DMEM $+10 \%$ FBS, STP, BDNF/NT-3-STP) and then switched to Neurocult ${ }^{\mathrm{TM}}$ differentiation for another 21 days. Differentiation of hDPSCs to neurons was assessed by immunofluorescence against immature (DCX) and mature (NeuN) neuronal markers, whereas differentiation to glial (Schwann) cells was assessed by P75 ${ }^{\mathrm{NTR}}$ and S100ß.

We found that preconditioning with BDNF/NT-3 rendered hDPSCs more responsive to neural differentiation (Fig. 6a-b). After 3 weeks of growth in Neurocult ${ }^{\mathrm{TM}}$ differentiation culture medium, nearly half $(48.18 \pm 2.82 \%)$ of BDNF/NT-3-treated cells showed a clear nuclear staining for NeuN, indicative of neuronal lineage commitment (Fig. 6b). This was corroborated with immunostaining of mature neuron marker MAP2 showing a $50.53 \pm 23.11 \%$ of positive cells (Supplementary Fig. 2a). Up to $66.2 \pm 31.3 \%$ hDPSCs were positive for tyrosine hydroxylase, a specific marker for dopaminergic neurons $(* * *=p<0.001$, KruskalWallis, Supplementary Fig. 2d), and $34.8 \pm 4.83 \%$ were positive for GABA neurotransmitter ${ }^{* *}=\mathrm{p}<0.0044$, Kruskal-Wallis, Supplementary Fig. 2e). On the other hand, we found $43.84 \pm 10.60 \%$ of cells that showed the immature neuronal marker DCX (Fig. 6c). Similarly, about the other half of the cultured cells $(54.88 \pm 4.60 \%)$ were positive for the Schwann cell marker S100 $\beta$ (Fig. 6e), and a majority of cells showed labeling for p75 $5^{\text {NTR }}(73.21 \pm 2.69 \%$; Fig. 6f). In contrast, only a tiny fraction of cells grown in DMEM $+10 \%$ FBS showed such adult neural cell characteristics $(5.98 \pm 2.59 \%$ NeuN+; 6.76 $\pm 4.06 \%$ DCX+; $6.28 \pm 3.01 \%$ S100ß; Fig. $6 \mathrm{~b}-\mathrm{e}$ ) and only $24.35 \pm 3.37 \%$ of them showed p $75^{\mathrm{NTR}}$ labeling (Fig. 6f). These results indicated that hDPSCs preconditioned with BDNF/NT-3-STP medium showed a better responsiveness 


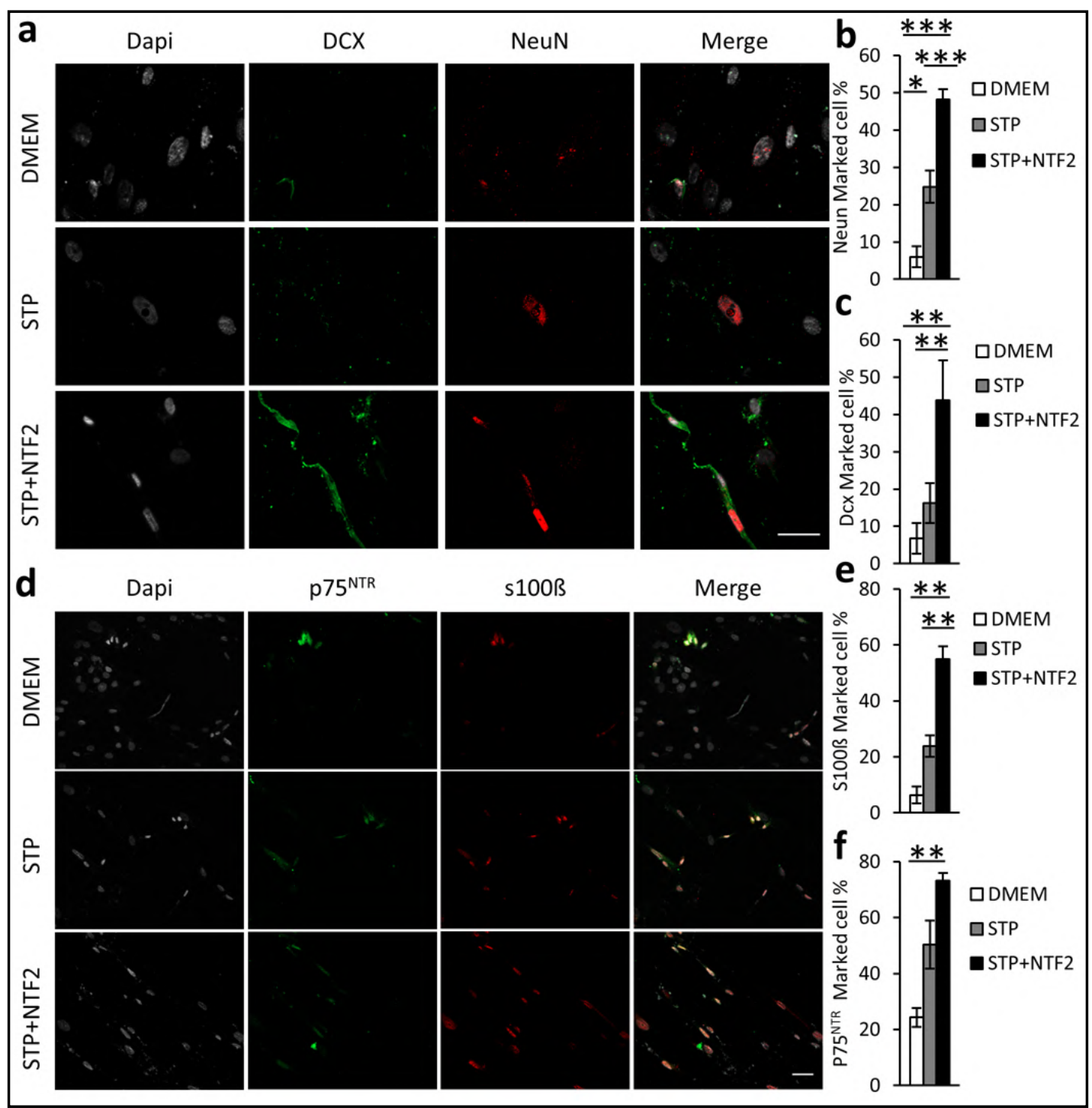

Fig. 6. Differentiation of hDPSCs grown in DMEM+10\% FBS, STP and STP/NTF2 media to neuronal and gliallineage cells: a) After a preconditioning growth phase of hDSPSCs in different culture media, neuronal and glial differentiation of hDPSCs was induced by culturing cells with the neural-inductive medium Neurocult Differentiation for 3 weeks. Cells were stained for the immature neuronal marker DCX (green), and mature neuronal marker NeuN (Red). Scale Bar 50 $\mathrm{m}$. b-c) Graph showing positively marked cell percentage for NeuN and DCX. d) hDPSCs were stained with the Schwann cell markers, P75 ${ }^{\text {NTR }}$ (green) and S100ß (Red). Scale Bar $50 \mu \mathrm{m}$. e-f) Graph showing percentage of positive cells for S100ß and P75 ${ }^{\mathrm{NTR}}$. All statistics were analyzed by ANOVA following by Scheffe post-hoc analysis ${ }^{*}=\mathrm{p}<0.05,{ }^{* *}=\mathrm{p}<0.01,{ }^{* * *} \mathrm{p}<0.001$. Experiments were performed in triplicate.

to the neural differentiation protocol, with a higher proportion of cells expressing neuronal markers than hDPSCs grown in standard serum containing medium.

\section{Discussion}

Stem cells and especially mesenchymal stem cells have become not only a promising but also a realistic option for next generation cell therapies to treat irreversible nerve tissue injury [58]. Among the different types of mesenchymal stem cells that can be found within 


\section{Cellular Physiology Cell Physiol Biochem 2019;52:1361-1380

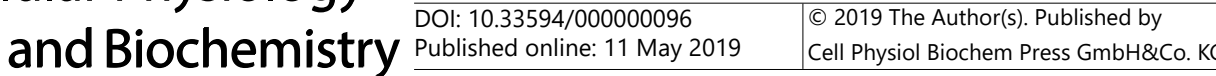 \\ Luzuriaga et al.: BDNF and NT3 Reprogram Human Dental Pulp Stem Cells to Neural \\ Crest Progenitors}

the adult human body, ectomesenchymal NC-derived stem cells derived from dental tissues, such as hDPSCs, appear particularly attractive to this purpose because of their possibility of extraction with low invasiveness, amenability to autologous graft, as well as their shared embryonic origin with the nerve system itself $[9,15]$.

Several researchers have described important phenotypic changes of hDPSCs when these cells are cultured in different serum-free media, in particular to what concerns floating sphere/dentosphere generation [27, 42,43]. This shows that hDPSCs can mimic the way both central NSC and peripheral neural crest stem cells behave in vitro, in the same or related serum-free media [33, 34, 59]. DMEM supplemented with 10-20\% FBS has been traditionally regarded as a gold standard for hDPSCs culture, owing to high cell amplification rates and a long-term maintenance of mesenchymal stem cell phenotype, but this is not appropriate for the generation of neural cells. Moreover, continuous presence of FBS is also associated with a plastic-adherent cell growth and a spontaneous differentiation of hDPSCs to osteoblasts/ odontoblasts after serial culture passaging $[35,36]$. Serum incorporation during stem cell culture procedure might also cause allergies and immune rejection of grafted cells, making its use challenging for nerve cell therapy $[37,38]$.

Despite the obvious differences in cell growth and culture characteristics, in our hands hDPSCs presented a near identical expression of mesenchymal and neural stem cell markers regardless of the employed culture medium. Thus, both serum-exposed adherent hDPSCs and serum-free dentosphere hDPSCs showed a generalized near $100 \%$ expression of the mesenchymal stem markers CD90, CD105 and CD73, together with the neural stem marker Nestin. This particular profile of markers is characteristic of NC-derived ectomesenchymal cells. Although as mesenchymal phenotype cells, hDPSCs have the preferential ability to differentiate to specialized connective tissue lineages, including bone, dentin, cartilage and adipose tissue [12], these stem cells are originally derived from early $\mathrm{NC}$ precursors that reside in perivascular locations within the dental pulp [23, 60, 61]. NC precursors constitute a small population of Sox $10+, \mathrm{p}^{\mathrm{NTR}}+$ and HNK1+ cells within the dental pulp tissue, which have the capacity to give rise to both neural and non-neural cell lineages [23, 33]. Thus, an important question was whether hDPSCs initially cultured with FBS still retained the ability to reverse their acquired in vitro ectomesenchymal phenotype, and be reprogrammed to early NC precursors with the capacity to give rise to populations of neural cells. In this work, we found this is indeed possible, when combining serum-free culture media with a stimulation of hDPSCs with BDNF and NT-3 neurotrophins for 7 days.

Histointegrity is one the most important aspects of cell therapy. The success of the graft of foreign cells in a host tissue is given by the capacity of these cells to adapt to the new surrounding environment. This adaptation capacity is described as the ability of cells to generate functional interactions and exchanges of signals in the place they are grafted $[62,63]$. In neural tissue, the establishment and/or regeneration of nerve connectivity depend on intercellular communication through neurotransmitters. In particular, excitatory neurotransmission through both GABA and glutamate is fundamental for the fine-tuning of synaptic connections during development $[64,65]$. For this reason, any cell to be grafted to regenerate nerve tissue should ideally detect and respond to those neurotransmitters, and thus interplay coordinately with host neural cells. Thus, in the context of cell therapy it is important to assess if hDPSCs are able to respond to different neurotransmitters. We found that hDPSCs grown in both serum-containing and serum-devoid conditions expressed mRNAs for different subunits of ionotropic neurotransmitter receptors. These were also functional, because they produced clear cytoplasm $\mathrm{Ca}^{2+}$ rises in subsets of hDPSCs after their stimulation with specific agonists. In addition, hDPSCs in both DMEM+10\% FBS and STP media also presented a high expression of Connexin (Cx26, Cx43) and Pannexin (Pnx1) subunits. We observed propagating $\mathrm{Ca}^{2+}$ waves under cell confluence, which is another shared characteristic with developing neural networks in vivo [66-69]. In addition, by live-cell $\mathrm{Ca}^{2+}$ imaging techniques we confirmed the results of other groups describing the presence of functional Bay-K-sensitive L-type voltage dependent calcium channels in hDPSCs [70]. Thus, in this work we show that hDPSCs express a good repertoire of neurotransmitter receptors, 


\section{Cellular Physiology Cell Physiol Biochem 2019;52:1361-1380

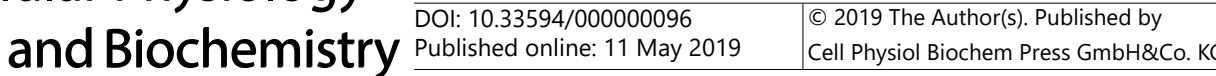 \\ Luzuriaga et al.: BDNF and NT3 Reprogram Human Dental Pulp Stem Cells to Neural \\ Crest Progenitors}

voltage-dependent channels, GAP junctions, and the ability to generate synchronous $\mathrm{Ca}^{2+}$ waves in vitro, in response to depolarization and the stimulation of kainate and ATP receptors. All these characteristics may render benefits with regard to the functional integration of grafted hDPSCs within nerve tissues.

Neurotrophins and their receptors are also essential in nerve signaling. It has been long described their effect in neural stem cell differentiation, neuronal survival, synaptogenesis and synapse plasticity [71-73]. Unexpectedly, we found that hDPSCs grown as dentospheres in serum-free STP medium presented significantly higher levels of mRNA expression for NTRK2 and NTRK3, two important high-affinity neurotrophin receptors with Tyrosine Kinase activity. Mesenchymal stem cells, in particular hDPSCs, produce and secrete large amounts of neurotrophins [74], which may account for neuroprotective abilities [75, 76]. In this work, we also showed that hDPSCs grown in different media were able to express $N G F$, $B D N F$ and $N T-3$. However, until now little if any information was available about the presence of neurotrophin receptors in hDPSCs, and their possible involvement in the regulation of hDPSCs homeostasis and/or differentiation. Addition of BDNF and NT-3, which are the respective ligands of NRTK2/TrkB and NRTK3/TrkC, as a medium supplement for 7 days to hDPSCs grown in STP, induced some remarkable changes in the phenotype of these cells: 1) hDPSCs recovered a high proliferation capacity, even in the absence of serum, 2) they increased the expression of pluripotency core factors NANOG, SOX2 and OCT4a. 3) this switch came along with an overexpression of NC progenitor markers $H N K 1$ and $p 75^{N T R}$ with respect to hDPSCs cultured in DMEM $+10 \%$ FBS. These results suggested that ectomesenchymal hDPSCs cultured with BDNF and NT3 in a serum free medium were reprogrammed one step back to become true NC progenitors.

NC progenitors are known to be present within dental pulp tissue [16, 23]. One major step of NC lineage specification consists on differentiation of NC progenitors into either neural-committed cells, or alternatively to ectomesenchymal stem cells. The former give rise to peripheral nerve system (PNS) neurons and Schwann cells, whereas the latter differentiate to other specialized connective tissues like bone, cartilage, and adipose tissue, among others. Importantly, the fate of $\mathrm{NC}$ progenitors in vitro depends on the presence or absence of serum in the culture medium [33]. Thus, serum presence favors ectomesenchymal differentiation, whereas its absence promotes neural differentiation. Then in the presence of $10 \%$ FBS in vitro, most NC progenitors tend to differentiate towards ectomesenchymal type, expressing typical markers such as STR0-1, CD90, CD73 and CD105, as it was indeed the case for our starting DPSC cultures (Fig. 1d). We show here that this ectomesenchymal conversion process is reversible. We found that previous exposure of hDPSCs to FBS, even if afterwards cells were cultured either with DMEM $+10 \%$ FBS or STP media, produced a generalized expression of mesenchymal markers that may suggest a lower capacity to give rise to neural lineages. To our surprise, the addition of BDNF and NT-3 in STP medium was sufficient to reverse this phenotype, changing the scenario dramatically and allowing hDPSCs to overexpress NC and pluripotency core factors. These changes have been attributed to an enhanced stemness [45].

To confirm the dedifferentiation towards NC or a more initial stemness stage, we investigated whether hDPSCs gained an improved capacity to give rise to neural (neuronal or glial), and non-neural (e.g. mesenchymal) cell lineages, thus losing the preconditioned response to differentiate towards osteoblasts after FBS exposure. BDNF/NT-3 treated hDPSCs cultured with standard protocols of osteoblastic (mesenchymal lineage) differentiation, by addition of dexamethasone, $\beta$-glycerolphosphate and ascorbate to the medium, did not retain the capacity to differentiate to osteoblasts and generate a mineralized bone matrix. In contrast, when cultured with differentiation (Neurocult ${ }^{\mathrm{TM}}$ ) media, BDNF/NT-3reprogrammed hDPSCs gave rise to significantly larger populations $(\sim 50 \%)$ of neuronallike cells (expressing NeuN, DCX, MAP2 and/or dopaminergic and GABAergic markers), and also to Schwann glial marker-expressing cells (p75 ${ }^{\text {NTR }}$, S100 $\beta$ ). In comparison, hDPSCs that were grown in DMEM+10\% FBS typically generated less than $10 \%$ of cells with these characteristics. The exposure of hDPSCs to BDNF and NT-3 for 7 days in STP medium was 


\section{Cellular Physiology Cell Physiol Biochem 2019;52:1361-1380 \begin{tabular}{ll|l} 
and Biochemistry & $\begin{array}{l}\text { DOl: 10.33594/000000096 } \\
\text { Published online: 11 May 2019 }\end{array}$ & $\begin{array}{l}\text { O } 2019 \text { The Author(s). Published by } \\
\text { Cell Physiol Biochem Press GmbH\&Co. KG }\end{array}$ \\
\cline { 2 - 3 } &
\end{tabular} \\ Luzuriaga et al.: BDNF and NT3 Reprogram Human Dental Pulp Stem Cells to Neural Crest Progenitors}

Fig. 7. Summary of research findings: Stem Cells within dental pulp tissue, collectively termed Dental Pulp Stem Cells or DPSCs, comprise actually a mixture of early HNK1+ and $\mathrm{p}^{2} 5^{\mathrm{NTR}_{+}} \mathrm{NC}$ progenitors, which are able to give rise to neuronal and glial cells, together with further committed ectomesenchymal stem cells, which are specialized to differentiate to connective tissue cell lineages. Under standard in vitro culture media containing FBS, hDPSCs tend to differentiate to ectomesenchymal phenotypes, characterized by the expression of CD90, CD73, CD105 and Collagen I markers. This differentiation

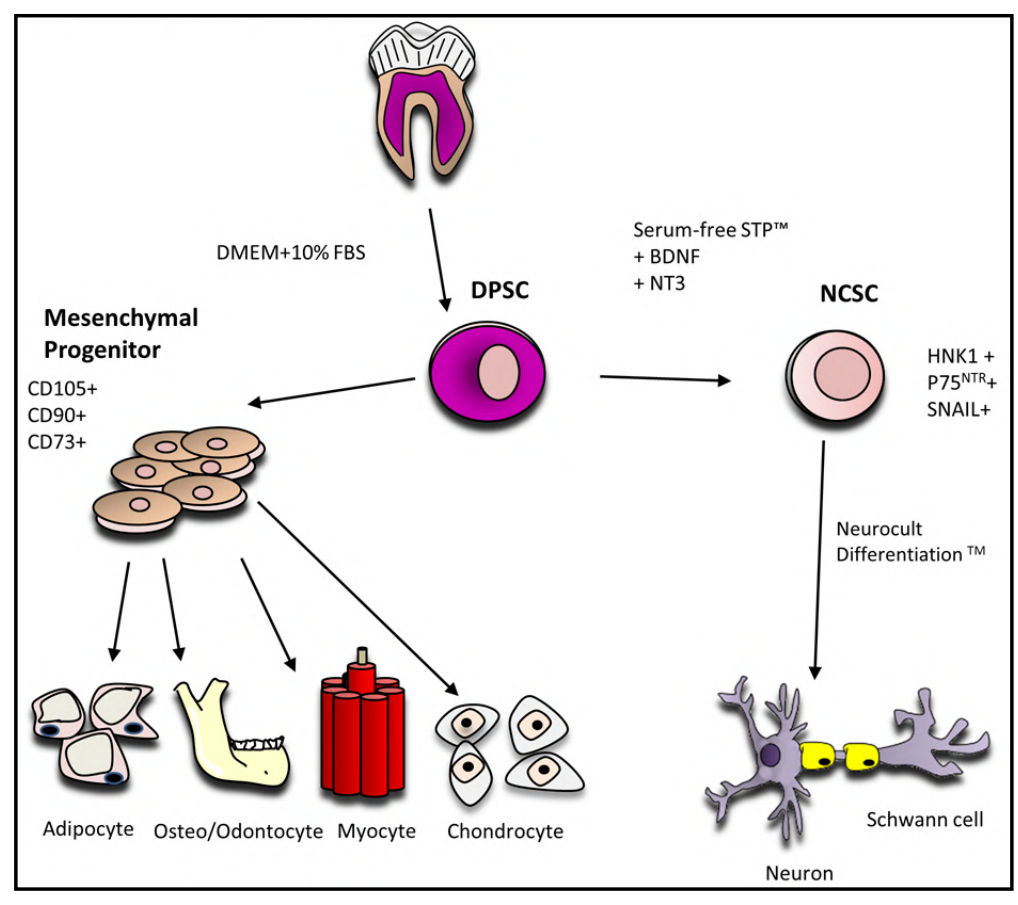
process may be reverted by culturing hDPSCs with a serum free (STP ${ }^{\mathrm{Tm}}$ ) medium, supplemented with BDNF and NT-3 neurotrophins. Under these conditions, hDPSCs highly upregulate NC progenitor markers HNK1 and $\mathrm{p} 75^{\mathrm{NTR}}$ and acquire an enhanced capacity to give rise to neuronal and glial lineage cells.

sufficient to reprogram these cells to acquire a more prominent NC progenitor phenotype, becoming more competent for direct neural differentiation.

One of the most remarkable aspects of the current work is that a serum-free medium combined with BDNF and NT-3 is enough to reprogram ectomesenchymal hDPSCs to early NC progenitors. These progenitors can in turn generate neurons and/or glial cells when exposed to other standard Neurobasal and/or B27 containing serum-free media. Previous reports had already described a very efficient generation of neuron-like cells and Schwann cells out of hDPSCs [24, 27, 28]. However, those protocols very often included aggressive treatments involving indiscriminate epigenetic reprogramming (5-azacitidine) and/or manipulation of cellular signaling pathways (dbcAMP, trans-retinoic acid, etc.). Here we present a twostep alternative protocol, whose principal novelty is the physiological stimulation of hDPSCs with BDNF and NT-3 neurotrophins to induce a partial reprogramming of ectomesenchymal hDPSCs to NC progenitors. The main findings of this work can be found summarized in Fig. 7.

\section{Conclusion}

In conclusion, the present work sheds light on the important role of neurotrophin signaling in hDPSCs, for the preservation of a multipotential NC phenotype in these cells. These results may have a direct application to medical therapy because they represent a significant improvement of current existing protocols to obtain populations of autologous neural cells out of hDPSCs. Given that the reprogramming of hDPSCs takes place safely and in a serum-free medium, this and other related protocols could hold a great promise for the clinical therapy of many so far yet incurable and irreversible nerve tissue lesions and diseases. 


\section{Cellular Physiology Cell Physiol Biochem 2019;52:1361-1380 \begin{tabular}{l|l|l} 
DOI: 10.33594/000000096 & ( 2019 The Author(s). Published by
\end{tabular} and BIOChemistry Published online: 11 May $2019 \quad$ Cell Physiol Biochem Press GmbH\&Co. KG \\ Crest Progenitors}

\section{Acknowledgements}

Authors would like to thanks to Díez A. for flow cytometry, Andrade, R. for image acquisition and all staff of the SGIKER of UPV/EHU. This work has been funded by the Spanish Ministry of Economy and Competitiveness SAF2015-70866-R; UPV/EHU (GIU16/66, UFI 11/44), Basque Government (GV/EJ; IT831-13) and by « Ramón y Cajal » program RYC-201313450 (JRP) and RYC 2012-11137 (JME); JL obtained a Ph.D. fellowship (PIF/13/268) from the University of the Basque Country. Author Contributions: J.L., I.I., V.U.E., P.G.G., P.C., F.U. and G.I.: conception and design; P.C., G.I., J.R.P., F.U. and J.L.: provision of study materials and manuscript writing; J.R.P., J.M.E., F.U., P.C., and G.I.: financial support; J.L., I.I., U.E.V., F.U. P.C., and G.I.: collection and/or assembly of data, J.L., I.I., U.E.V, P.G.G., J.R.P. and G.I., data analysis and interpretation; J.L., P.C., V.U.E., J.M.E., F.U., I.I., P.G.G., G.I. and J.R.P., manuscript discussion and final approval of manuscript. The authors have no ethical conflicts to disclose.

\section{Disclosure Statement}

The authors have no conflicts of interest to declare.

\section{References}

- 1 Chen Z, Wang Y, Shi C: Therapeutic Implications of Newly Identified Stem Cell Populations From the Skin Dermis. Cell Transplant 2015;24:1405-1422.

- 2 Cramer JM, Thompson T, Geskin A, LaFramboise W, Lagasse E: Distinct human stem cell populations in small and large intestine. PLoS One2015;10:e0118792.

- 3 Hoffman RM: Human Hair Follicle Associated-Pluripotent (hHAP) Stem Cells Differentiate to Cardiac Muscle Cells. Methods Mol Biol 2019;1879:385-392.

4 Kriegstein A, Alvarez-Buylla A: The Glial Nature of Embryonic and Adult Neural Stem Cells. Annu Rev Neurosci 2009;32:149-184.

- 5 Mahmoudifar N, Doran PM: Mesenchymal Stem Cells Derived from Human Adipose Tissue. Methods Mol Biol 2015;1340:53-64.

- 6 Pontikoglou C, Deschaseaux F, Sensebé L, Papadaki HA: Bone marrow mesenchymal stem cells: biological properties and their role in hematopoiesis and hematopoietic stem cell transplantation. Stem Cell Rev 2011;7:569-589.

- 7 Barber PC: Neurogenesis and regeneration in the primary olfactory pathway of mammals. Bibl Anat 1982;12-25.

- 8 Atari M, Gil-Recio C, Fabregat M, García-Fernández D, Barajas M, Carrasco MA, Jung. HS, Alfaro FH, Casals N, Prosper F, Ferrés-Padró E, Giner L: Dental pulp of the third molar: a new source of pluripotent-like stem cells. J Cell Sci 2012;125:3343-3356.

- 9 Aurrekoetxea M, Garcia-Gallastegui P, Irastorza I, Luzuriaga J, Uribe-Etxebarria V, Unda F, Ibarretxe G: Dental pulp stem cells as a multifaceted tool for bioengineering and the regeneration of craniomaxillofacial tissues. Front Physiol 2015;6:289.

- 10 Trowbridge HO: Pulp biology: progress during the past 25 years. Aust Endod J 2003;29:5-12.

- 11 Gronthos S, Mankani M, Brahim J, Robey PG, Shi S: Postnatal human dental pulp stem cells (DPSCs) in vitro and in vivo. Proc Natl Acad Sci USA 2000;97:13625-13630.

12 Gronthos S, Brahim J, Li W, Fisher LW, Cherman N, Boyde A, DenBesten P, Robey PG: Stem cell properties of human dental pulp stem cells. J Dent Res 2002;81:531-535.

- 13 d'Aquino R, Graziano A, Sampaolesi M, Laino G, Pirozzi G, De Rosa A, Papaccio G: Human postnatal dental pulp cells co-differentiate into osteoblasts and endotheliocytes: a pivotal synergy leading to adult bone tissue formation. Cell Death Differ 2007;14:1162-1171.

- 14 Batouli S, Miura M, Brahim J, Tsutsui TW, Fisher LW, Gronthos S, Robey PG, Shi S: Comparison of stem-cellmediated osteogenesis and dentinogenesis. J Dent Res 2003;82:976-981. 


\section{Cellular Physiology Cell Physiol Biochem 2019;52:1361-1380 \begin{tabular}{c|l}
\cline { 2 - 3 } DOI: 10.33594/000000096 & (c) 2019 The Author(s). Published by
\end{tabular} and Biochemistry Published online: 11 May $2019 \quad$ Cell Physiol Biochem Press GmbH\&Co. KG \\ Luzuriaga et al.: BDNF and NT3 Reprogram Human Dental Pulp Stem Cells to Neural \\ Crest Progenitors}

- 15 Ibarretxe G, Crende O, Aurrekoetxea M, García-Murga V, Etxaniz J, Unda F: Neural crest stem cells from dental tissues: a new hope for dental and neural regeneration. Stem Cells Int 2012;2012:103503.

- 16 Janebodin K, Horst OV, Ieronimakis N, Balasundaram G, Reesukumal K, Pratumvinit B, Reyes M: Isolation and characterization of neural crest-derived stem cells from dental pulp of neonatal mice. PLoS One 2011;6:e27526.

17 Kerkis I, Kerkis A, Dozortsev D, Stukart-Parsons GC, Gomes Massironi SM, Pereira LV, Caplan AI, Cerruti HF: Isolation and characterization of a population of immature dental pulp stem cells expressing OCT-4 and other embryonic stem cell markers. Cells Tissues Organs 2006;184:105-116.

18 Laino G, d’Aquino R, Graziano A, Lanza V, Carinci F, Naro F, Pirozzi G, Papaccio G: A new population of human adult dental pulp stem cells: a useful source of living autologous fibrous bone tissue (LAB). J Bone Miner Res 2005;20:1394-1402.

19 Laino G, Graziano A, d’Aquino R, Pirozzi G, Lanza V, Valiante S, De Rosa A, Naro F, Vivarelli E, Papaccio G: An approachable human adult stem cell source for hard-tissue engineering. J Cell Physiol 2006;206:693-701.

20 Bento LW, Zhang Z, Imai A, Nör F, Dong Z, Shi S, Araujo FB, Nör JE: Endothelial differentiation of SHED requires MEK1/ERK signaling. J Dent Res 2013;92:51-57.

21 Iohara K, Zheng L, Wake H, Ito M, Nabekura J, Wakita H, Nakamura H, Into T, Matsushita K, Nakashima M: A novel stem cell source for vasculogenesis in ischemia: subfraction of side population cells from dental pulp. Stem Cells 2008;26:2408-2418.

22 Janebodin K, Zeng Y, Buranaphatthana W, Ieronimakis N, Reyes M: VEGFR2-dependent angiogenic capacity of pericyte-like dental pulp stem cells. J Dent Res 2013;92:524-531.

23 Kaukua N, Shahidi MK, Konstantinidou C, Dyachuk V, Kaucka M, Furlan A, An Z, Wang L, Hultman I, Ahrlund-Richter L, Blom H, Brismar H, Lopes NA, Pachnis V, Suter U, Clevers H, Thesleff I, Sharpe P, Ernfors P, Fried K, Adameyko I: Glial origin of mesenchymal stem cells in a tooth model system. Nature 2014;513:551-554.

24 Martens W, Sanen K, Georgiou M, Struys T, Bronckaers A, Ameloot M, Phillips J, Lambrichts I: Human dental pulp stem cells can differentiate into Schwann cells and promote and guide neurite outgrowth in an aligned tissue-engineered collagen construct in vitro. FASEB J 2014;28:1634-1643.

25 Sakai VT, Zhang Z, Dong Z, Neiva KG, Machado MA, Shi S, Santos CF, Nör JE: SHED differentiate into functional odontoblasts and endothelium. J Dent Res 2010; 89:791-796.

26 Arthur A, Rychkov G, Shi S, Koblar SA, Gronthos S: Adult human dental pulp stem cells differentiate toward functionally active neurons under appropriate environmental cues. Stem Cells 2008;26:1787-1795.

27 Gervois P, Struys T, Hilkens P, Bronckaers A, Ratajczak J, Politis C, Brône B, Lambrichts I, Martens W: Neurogenic maturation of human dental pulp stem cells following neurosphere generation induces morphological and electrophysiological characteristics of functional neurons. Stem Cells Dev 2015;24:296311.

28 Király M, Porcsalmy B, Pataki A, Kádár K, Jelitai M, Molnár B, Hermann P, Gera I, Grimm WD, Ganss B, Zsembery A, Varga G: Simultaneous PKC and cAMP activation induces differentiation of human dental pulp stem cells into functionally active neurons. Neurochem Int 2009;55:323-332.

29 Nosrat IV, Smith CA, Mullally P, Olson L, Nosrat CA: Dental pulp cells provide neurotrophic support for dopaminergic neurons and differentiate into neurons in vitro; implications for tissue engineering and repair in the nervous system. Eur J Neurosci 2004;19:2388-2398.

30 Liu JA, Cheung M: Neural crest stem cells and their potential therapeutic applications. Dev Biol 2016;419:199-216.

31 Petersen J, Adameyko I: Nerve-associated neural crest: peripheral glial cells generate multiple fates in the body. Curr Opin Genet Dev 2017;45:10-14.

32 Bhatt S, Diaz R, Trainor PA: Signals and switches in Mammalian neural crest cell differentiation. Cold Spring Harb Perspect Biol 2013;5:pii:a008326.

33 Lee G, Kim H, Elkabetz Y, Al Shamy G, Panagiotakos G, Barberi T, Tabar V, Studer L: Isolation and directed differentiation of neural crest stem cells derived from human embryonic stem cells. Nat Biotechnol 2007;25:1468-1475.

34 Fournier BP, Loison-Robert LS, Ferré FC, Owen GR, Larjava H, Häkkinen L: Characterisation of human gingival neural crest-derived stem cells in monolayer and neurosphere cultures. Eur Cell Mater 2016;31:40-58. 


\section{Cellular Physiology Cell Physiol Biochem 2019;52:1361-1380 \begin{tabular}{l|l|l}
\cline { 2 - 3 } DOI: 10.33594/000000096 & (c) 2019 The Author(s). Published by
\end{tabular} and Biochemistry Published online: 11 May $2019 \quad$ Cell Physiol Biochem Press GmbH\&Co. KG \\ Luzuriaga et al.: BDNF and NT3 Reprogram Human Dental Pulp Stem Cells to Neural \\ Crest Progenitors}

35 Pisciotta A, Riccio M, Carnevale G, Beretti F, Gibellini L, Maraldi T, Cavallini GM, Ferrari A, Bruzessi G, De Pol A: Human serum promotes osteogenic differentiation of human dental pulp stem cells in vitro and in vivo. PLoS One 2012; 7:e50542.

- 36 Yu J, He H, Tang C, Zhang G, Li Y, Wang R, Shi J, Jin Y: Differentiation potential of STRO-1+ dental pulp stem cells changes during cell passaging. BMC Cell Biol 2010;11:32.

- 37 Gregory CA, Reyes E, Whitney MJ, Spees JL: Enhanced engraftment of mesenchymal stem cells in a cutaneous wound model by culture in allogenic species-specific serum and administration in fibrin constructs. Stem Cells 2006;24:2232-2243.

- 38 Horwitz EM, Gordon PL, Koo WKK, Marx JC, Neel MD, McNall RY, Muul L, Hofmann T: Isolated allogeneic bone marrow-derived mesenchymal cells engraft and stimulate growth in children with osteogenesis imperfecta: Implications for cell therapy of bone. Proc Natl Acad Sci USA 2002;99:8932-8937.

39 Pacini S: Deterministic and stochastic approaches in the clinical application of mesenchymal stromal cells (MSCs). Front Cell Dev Biol 2014;2:50.

40 Deleyrolle LP, Reynolds BA: Isolation, expansion, and differentiation of adult Mammalian neural stem and progenitor cells using the neurosphere assay. Methods Mol Biol 2009;549:91-101.

41 Pineda JR, Daynac M, Chicheportiche A, Cebrian-Silla A, Sii Felice K, Garcia-Verdugo JM, Boussin FD, Mouthon MA: Vascular-derived TGF- $\beta$ increases in the stem cell niche and perturbs neurogenesis during aging and following irradiation in the adult mouse brain. EMBO Mol Med 2013;5:548-562.

- 42 Bonnamain V, Thinard R, Sergent-Tanguy S, Huet P, Bienvenu G, Naveilhan P, Farges JC, Alliot-Licht B: Human dental pulp stem cells cultured in serum-free supplemented medium. Front Physiol 2013;4:357.

- 43 Lee SH, Inaba A, Mohindroo N, Ganesh D, Martin CE, Chugal N, Kim RH, Kang MK, Park NH, Shin KH: Threedimensional Sphere-forming Cells Are Unique Multipotent Cell Population in Dental Pulp Cells. J Endod 2017;43:1302-1308.

- 44 Luzuriaga J, Pastor-Alonso O, Encinas JM, Unda F, Ibarretxe G, Pineda JR: Human Dental Pulp Stem Cells Grown in Neurogenic Media Differentiate Into Endothelial Cells and Promote Neovasculogenesis in the Mouse Brain. Front Physiol 2019;10:347.

45 Uribe-Etxebarria V, Luzuriaga J, García-Gallastegui P, Agliano A, Unda F, Ibarretxe G: Notch/Wnt crosssignalling regulates stemness of dental pulp stem cells through expression of neural crest and core pluripotency factors. Eur Cell Mater 2017;34:249-270.

46 Livak KJ, Schmittgen TD: Analysis of relative gene expression data using real-time quantitative PCR and the 2(-Delta Delta C(T)) Method. Methods 2001;25:402-408.

47 Purves D, Snider WD, Voyvodic JT: Trophic regulation of nerve cell morphology and innervation in the autonomic nervous system. Nature 1988;336:123-128.

- 48 Eide FF, Lowenstein DH, Reichardt LF: Neurotrophins and their receptors--current concepts and implications for neurologic disease. Exp Neurol 1993;121:200-214.

49 Morfini G, DiTella MC, Feiguin F, Carri N, Cáceres A: Neurotrophin-3 enhances neurite outgrowth in cultured hippocampal pyramidal neurons. J Neurosci Res 1994;39:219-232.

- 50 Lim JY, Park SI, Oh JH, Kim SM, Jeong CH, Jun JA, Lee KS, Oh W, Lee JK, Jeun SS: Brain-derived neurotrophic factor stimulates the neural differentiation of human umbilical cord blood-derived mesenchymal stem cells and survival of differentiated cells through MAPK/ERK and PI3K/Akt-dependent signaling pathways. J Neurosci Res 2008;86:2168-2178.

51 Bibel M, Hoppe E, Barde YA: Biochemical and functional interactions between the neurotrophin receptors trk and p75NTR. EMBO J 1999;18:616-622.

52 Benedetti M, Levi A, Chao MV: Differential expression of nerve growth factor receptors leads to altered binding affinity and neurotrophin responsiveness. Proc Natl Acad Sci USA 1993;90:7859-7863.

53 Ulrich R, Imbschweiler I, Kalkuhl A, Lehmbecker A, Ziege S, Kegler K, : Transcriptional profiling predicts overwhelming homology of Schwann cells, olfactory ensheathing cells, and Schwann cell-like glia. Glia 2014;62:1559-1581.

54 Conner JM, Varon S: Maintenance of sympathetic innervation into the hippocampal formation requires a continuous local availability of nerve growth factor. Neuroscience 1996;72:933-945.

- 55 Sofroniew MV, Howe CL, Mobley WC: Nerve growth factor signaling, neuroprotection, and neural repair. Annu Rev Neurosci 2001;24:1217-1281.

56 Del Barrio MG, Nieto MA: Relative expression of Slug, RhoB, and HNK-1 in the cranial neural crest of the early chicken embryo. Dev Dyn 2004;229:136-139. 


\section{Cellular Physiology Cell Physiol Biochem 2019;52:1361-1380 \begin{tabular}{c|l}
\hline DOI: 10.33594/000000096 & (c) 2019 The Author(s). Published by
\end{tabular} and Biochemistry Published online: 11 May $2019 \quad$ Cell Physiol Biochem Press GmbH\&Co. KG \\ Luzuriaga et al.: BDNF and NT3 Reprogram Human Dental Pulp Stem Cells to Neural \\ Crest Progenitors}

- 57 Louis SA, Reynolds BA: Generation and differentiation of neurospheres from murine embryonic day 14 central nervous system tissue. Methods Mol Biol 2005;290:265-280.

- 58 Vaquero J, Zurita M, Rico MA, Aguayo C, Bonilla C, Marin E, Tapiador N, Sevilla M, Vazquez D, Carballido J, Fernandez C, Rodriguez-Boto G, Ovejero M, Neurological Cell Therapy Group from Puerta de HierroMajadahonda Hospital: Intrathecal administration of autologous mesenchymal stromal cells for spinal cord injury: Safety and efficacy of the 100/3 guideline. Cytotherapy 2018;20:806-819.

59 Reynolds BA, Weiss S: Generation of neurons and astrocytes from isolated cells of the adult mammalian central nervous system. Science 1992;255:1707-1710.

60 Janebodin K, Reyes M: Neural Crest-Derived Dental Pulp Stem Cells Function as Ectomesenchyme to Support Salivary Gland Tissue Formation. Dentistry 2012;S13:001.

61 Shi S, Gronthos S: Perivascular niche of postnatal mesenchymal stem cells in human bone marrow and dental pulp. J Bone Miner Res 2003;18:696-704.

62 Guerzon ER, Pereira BP, Bhavanam K, Khin ZA, Nathan SS: Collagen membranes for host-graft integration: an animal study. J Orthop Surg (Hong Kong) 2011;19:151-156.

63 Muschler GF, Nakamoto C, Griffith LG: Engineering principles of clinical cell-based tissue engineering. J Bone Joint Surg Am 2004;86-A:1541-1558.

- 64 Ben-Ari Y: Developing networks play a similar melody. Trends Neurosci 2001;24:353-360.

- 65 Egorov AV, Draguhn A: Development of coherent neuronal activity patterns in mammalian cortical networks: common principles and local hetereogeneity. Mech Dev 2013;130:412-423.

66 Bruzzone R, Hormuzdi SG, Barbe MT, Herb A, Monyer H: Pannexins, a family of gap junction proteins expressed in brain. Proc Natl Acad Sci USA 2003;100:13644-13649.

67 Harrison JF, Rinne ML, Kelley MR, Druzhyna NM, Wilson GL, Ledoux SP: Altering DNA Base Excision Repair: Use of Nuclear and Mitochondrial-Targeted N-Methylpurine DNA Glycosylase to Sensitize Astroglia to Chemotherapeutic Agents. Glia 2007;55:1416-1425.

68 Nadarajah B, Jones AM, Evans WH, Parnavelas JG: Differential Expression of Connexins during Neocortical Development and Neuronal Circuit Formation. J Neurosci 1997;17:3096-3111.

69 Ray A, Zoidl G, Weickert S, Wahle P, Dermietzel R: Site-specific and developmental expression of pannexin1 in the mouse nervous system. Eur J Neurosci 2005;21:3277-3290.

70 Ellis KM, O'Carroll DC, Lewis MD, Rychkov GY, Koblar SA: Neurogenic potential of dental pulp stem cells isolated from murine incisors. Stem Cell Res Ther 2014;5:30.

71 Bibel M, Barde YA: Neurotrophins: key regulators of cell fate and cell shape in the vertebrate nervous system. Genes Dev 2000;14:2919-2937.

72 Oliveira SLB, Pillat MM, Cheffer A, Lameu C, Schwindt TT, Ulrich H: Functions of neurotrophins and growth factors in neurogenesis and brain repair. Cytometry A 2013;83:76-89.

73 Poo MM: Neurotrophins as synaptic modulators. Nat Rev Neurosci 2001;2:24-32.

74 Mead B, Logan A, Berry M, Leadbeater W, Scheven BA: Paracrine-mediated neuroprotection and neuritogenesis of axotomised retinal ganglion cells by human dental pulp stem cells: comparison with human bone marrow and adipose-derived mesenchymal stem cells. PLoS One 2014;9:e109305.

75 Ratajczak J, Bronckaers A, Dillen Y, Gervois P, Vangansewinkel T, Driesen RB, Wolf E, Lambrichts I, Hilkens P: The Neurovascular Properties of Dental Stem Cells and Their Importance in Dental Tissue Engineering. Stem Cells Int 2016;2016:9762871.

76 Song M, Lee JH, Bae J, Bu Y, Kim EC: Human Dental Pulp Stem Cells Are More Effective Than Human Bone Marrow-Derived Mesenchymal Stem Cells in Cerebral Ischemic Injury. Cell Transplant 2017;26:1001-1016. 